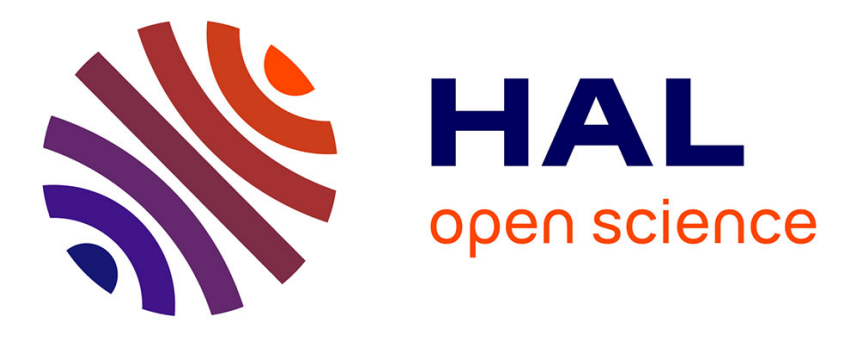

\title{
[4]Cyclo-N-alkyl-2,7-carbazoles: Influence of the Alkyl Chain Length on the Structural, Electronic, and Charge Transport Properties
}

Fabien Lucas, Nemo Mcintosh, Emmanuel Jacques, Christophe Lebreton, Benoît Heinrich, Bertrand Donnio, Olivier Jeannin, Joëlle Rault-Berthelot, Cassandre Quinton, Jérôme Cornil, et al.

\section{To cite this version:}

Fabien Lucas, Nemo Mcintosh, Emmanuel Jacques, Christophe Lebreton, Benoît Heinrich, et al.. [4]Cyclo-N-alkyl-2,7-carbazoles: Influence of the Alkyl Chain Length on the Structural, Electronic, and Charge Transport Properties. Journal of the American Chemical Society, 2021, 143 (23), pp.88048820. 10.1021/jacs.1c03240 . hal-03282728

\section{HAL Id: hal-03282728 \\ https://hal.science/hal-03282728}

Submitted on 10 Sep 2021

HAL is a multi-disciplinary open access archive for the deposit and dissemination of scientific research documents, whether they are published or not. The documents may come from teaching and research institutions in France or abroad, or from public or private research centers.
L'archive ouverte pluridisciplinaire HAL, est destinée au dépôt et à la diffusion de documents scientifiques de niveau recherche, publiés ou non, émanant des établissements d'enseignement et de recherche français ou étrangers, des laboratoires publics ou privés. 


\title{
[4]Cyclo- $N$-alkyl-2,7-carbazoles: Influence of the alkyl chain length on the structural, electronic and charge transport properties
}

\author{
Fabien Lucas, ${ }^{\mathrm{a}}$ Nemo McIntosh, ${ }^{\mathrm{b}}$ Emmanuel Jacques, ${ }^{\mathrm{c}}$ Christophe Lebreton, ${ }^{\mathrm{c}}$ Benoît Heinrich, ${ }^{\mathrm{d}}$ Bertrand \\ Donnio, ${ }^{\mathrm{d}}$ Olivier Jeannin, ${ }^{\mathrm{a}}$ Joëlle Rault-Berthelot, ${ }^{\mathrm{a}}$ Cassandre Quinton, ${ }^{\mathrm{a}}$ Jérôme Cornil, ${ }^{\mathrm{b}}$ Cyril Poriel ${ }^{\mathrm{a}}$ \\ a Univ Rennes, CNRS, ISCR-UMR 6226, F-35000 Rennes, France \\ email: cyril.poriel@univ-rennes1.fr \\ b Laboratory for Chemistry of Novel Materials, University of Mons, Mons, Belgium \\ c Univ Rennes, CNRS, IETR-UMR 6164, F-35000 Rennes, France \\ d Institut de Physique et Chimie des Matériaux de Strasbourg (IPCMS), UMR 7504, CNRS-Université de Strasbourg, 23 rue \\ du Loess, BP 43, 67034 Strasbourg Cedex 2, France
}

Keywords: nanorings, organic semiconductor, charge transport, bridged cyclo-oligophenylenes, structure-properties relationship, molecular dynamics, density functional theory, curved $\pi$-conjugated system

\begin{abstract}
Macrocycles possessing radially oriented $\pi$-orbitals have experienced a fantastic development. However, their incorporation in organic electronic devices remains very scarce. In this work, we aim at bridging the gap between organic electronics and nanorings by reporting the first detailed structure-properties-device performance relationship study of organic functional materials based on a nanoring system. Three [4] cyclo- $N$-alkyl-2,7-carbazoles bearing different alkyl chains on their nitrogen atoms have been synthesized and characterized by combined experimental and theoretical approaches. This study includes electrochemical, photophysical, thermal and structural solid-state measurements and charge transport properties investigations. An optimized protocol of the Pt approach has been developed to synthesize the [4]-cyclocarbazoles in high yield (52-64\%), of great interest for further development of nanorings especially in materials science. The charge transport properties of [4]-cyclocarbazoles and a model compound, [8]-cycloparaphenylene ([8]CPP), have been studied. Although no field effect (FE) mobility was recorded for benchmark [8]CPP, FE mobility values of ca $10^{-5} \mathrm{~cm}^{2} . \mathrm{V}^{-1} \cdot \mathrm{s}^{-1}$ were recorded for the [4]-cyclocarbazoles. The characteristics (threshold voltage $\mathrm{V}_{\mathrm{TH}}$, subthreshold swing SS, trapping energy $\Delta \mathrm{E}$ ) recorded for the three[4]-cyclocarbazoles appear to be modulated by the alkyl chain length borne by the nitrogen atoms. Remarkably, the space-charge-limited current mobilities measured for the [4]-cyclocarbazoles are about 3 orders of magnitude higher than that of [8]CPP $\left(1.37 / 2.78 \times 10^{-4}\right.$ for the [4]-cyclocarbazoles $v s 1.21 \times 10^{-7} \mathrm{~cm}^{2} . \mathrm{V}^{-1} . \mathrm{s}^{-1} \mathrm{for}$ [8]CPP) highlighting the strong effect of nitrogen bridges on the charge transport properties. The whole study opens the way to the use of nanorings in electronics, which is now the next step of their developments.
\end{abstract}

\section{Introduction}

Since their discoveries in $2008,{ }^{1}$ hoop-shaped $\pi$-conjugated macrocycles, i.e. nanorings, have attracted a considerable attention worldwide due to their uncommon electronic properties arising from the radially distributed $\pi$ conjugation. ${ }^{2-7}$ Since then, various directions have already been taken to explore the potential of these fascinating molecular structures. These studies have mainly focused on the influence of the nanoring size and of the building units on the structural, electronic and chiral properties. ${ }^{3-14}$ As recently reviewed by Jasti and coworkers, ${ }^{15}$ nanorings can cover a broad range of applications including imaging tools in biology, ${ }^{16}$ complexing agent for single-walled carbon nanotubes ${ }^{17}$ or fullerenes, ${ }^{18-20}$ carbon-based porous material, ${ }^{21-}$ ${ }^{22}$ solid state emitters, ${ }^{11,23-24}$ or spin crossover compounds. ${ }^{25}$

Molecular nanorings are now considered for their potential applications in organic electronics. ${ }^{15}$ However, despite several theoretical reports published, ${ }^{26-29}$ only a few experimental data are yet available, essentially due to the difficulty to reach sufficient amount of nanorings for device incorporation. In early 2019, Houk and coworkers, ${ }^{26-28}$ and Negri and coworkers ${ }^{29}$ have predicted through a theoretical approach the strong potential of cyclo-para-phenylenes (CPPs), the flagship family of nanorings, and of Donor-Acceptor CPPs as high mobility materials. Indeed, CPPs display strong intermolecular interactions in the solid state, reminiscent to those found in fullerenes and carbon nanotubes, which can favor charge migration, resulting in high efficiency materials for electronics. However, despite the fantastic development of organic electronics in the last twenty years, ${ }^{30-31}$ the gap between nanorings and this field remains huge. ${ }^{32-33}$ For example, there is almost no available experimental data on charge carrier mobility of nanorings, which is a central notion in organic electronics ${ }^{34}$ for the three main types of devices, namely Organic Light-Emitting Diodes (OLED), Field-Effect Transistors (OFET) and solar cells. As far as we are aware, the literature only reports two examples. The first one has been reported in 2017 by Yamago and coworkers, ${ }^{35}$ with a 10[CPP] nanoring bearing butoxy chains. An electron mobility value of $4.5 \times 10^{-6} \mathrm{~cm}^{2} . \mathrm{V}^{-1} \cdot \mathrm{s}^{-1}$ was measured in an electron-only device using the space-charge-limited current (SCLC) technique. In 2019, the first incorporation of a nanoring as active layer in a p-type channel OFET has also been performed. ${ }^{36}$ The field effect (FE) mobility extracted, $1.1 \times 10^{-5} \mathrm{~cm}^{2} . \mathrm{V}^{-1} \cdot \mathrm{s}^{-1}$ has demonstrated that nanorings can be used in such devices, enlarging the molecular diversity of organic semiconductors (OSC). The corresponding OFET has displayed interesting characteristics such as a particularly low Subthreshold Swing (SS) of $2.2 \mathrm{~V} \mathrm{dec}^{-1}$. However, there is still a long way to go in terms of device efficiency and fundamental knowledge in this field.

In the present work based on a dual experimental and theoretical approach, we report on the very first detailed structure-properties relationship study of a nanoring series including their charge transport properties in both SCLC and OFET electronic devices. We describe the electrochemical, photophysical, thermal and structural properties of a series of

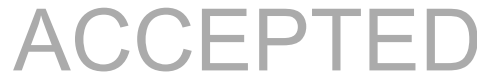


nanorings made with four carbazole units linked at their para positions C2 and C7, namely [4] cyclo- $N$-alkyl-2,7carbazoles. The alkyl chain length borne by the nitrogen atom has been systematically modified, i.e. [4]C-Et-Cbz, [4]C-Bu$\mathbf{C b z}$ and [4]C-Hex-Cbz, with ethyl, butyl and hexyl groups, respectively (Chart 1 top), in order to investigate the impact on the electronic and physical properties. Chain length engineering is indeed a well-known molecular design technique widely used in organic electronics to adjust both the properties in the solid state and the processability to improve the device performances. ${ }^{37-38}$ In the present [4]cyclocarbazoles, the chain has a significant impact on some physico-chemical properties while others are kept unchanged.

Furthermore, we present here an optimized synthetic approach of [4]-cyclocarbazoles, whose global yield has been increased eightfold as compared to the first synthesis published in 2016 by Yamago and coworkers (yield of $6 \%$ for a N-methylsubstituted cyclocarbazole from 2,7-dibromo- $\mathrm{N}$ methylcarbazole). ${ }^{39}$ In this emerging field of nanorings, the synthesis is obviously a crucial concern and particularly if an application is envisaged. Two model compounds - the unbridged [8]-cycloparaphenylene [8]CPP and the carbon-bridged [4]cyclo-9,9-diethyl-2,7-fluorene [4]C-diEt$\mathbf{F}^{23}$ analogues (Chart 1 Bottom) - were also studied in order to compare the impact of the presence and the nature of the bridge on the electronic and photophysical properties.

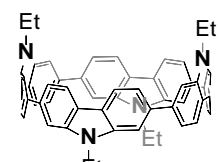

Et

[4]C-Et-Cbz

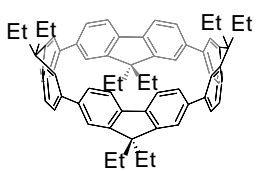

[4]C-diEt-F

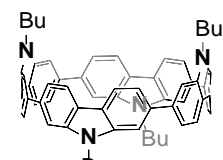

$\mathrm{Bu}$

[4]C-Bu-Cbz

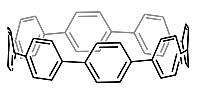

[8]CPP

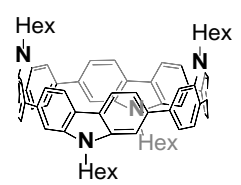

[4]C-Hex-Cbz
Chart 1. Nanorings investigated in this work.

The [4]-cyclocarbazoles and corresponding model [8]CPP have finally been incorporated as active layer in both p-type OFET and SCLC devices in order to study the mobility of the charge carriers in-plane and out-of-plane. Interestingly, no FE mobility was recorded for benchmark [8]CPP while a FE mobility value of ca $10^{-5} \mathrm{~cm}^{2} . \mathrm{V}^{-1} \cdot \mathrm{s}^{-1}$ was recorded for the three

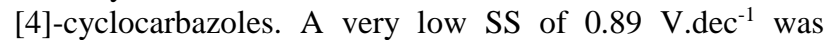
interestingly measured for [4]C-Bu-Cbz, highlighting the promising behavior of this molecule. In addition, the OFET characteristics (Threshold voltage $\mathrm{V}_{\mathrm{TH}}$, trapping energy $\Delta \mathrm{E}$...) recorded for the three [4]-cyclocarbazoles appear to be modulated by the alkyl chain length. Remarkably, the SCLC mobility measured for the [4]-cyclocarbazoles are ca 3 orders of magnitude higher than that of [8]CPP $\left(1.37 / 2.78 \times 10^{-4}\right.$ $\mathrm{cm}^{2} \cdot \mathrm{V}^{-1} \cdot \mathrm{s}^{-1}$ for the [4]-cyclocarbazoles vs $1.21 \times 10^{-7} \mathrm{~cm}^{2} \cdot \mathrm{V}^{-1} \cdot \mathrm{s}^{-}$ 1 for [8]CPP). These results have been contrasted by computing the electronic couplings between the nanorings at the DFT level in the single crystal structures as well as the associated thermally induced fluctuations. This study sheds light on the molecular and supramolecular parameters, which influence the charge transport in nanorings and shows how it can be significantly tuned by the nature of the building unit.

\section{Results and discussion}

\subsection{Synthetic investigations}

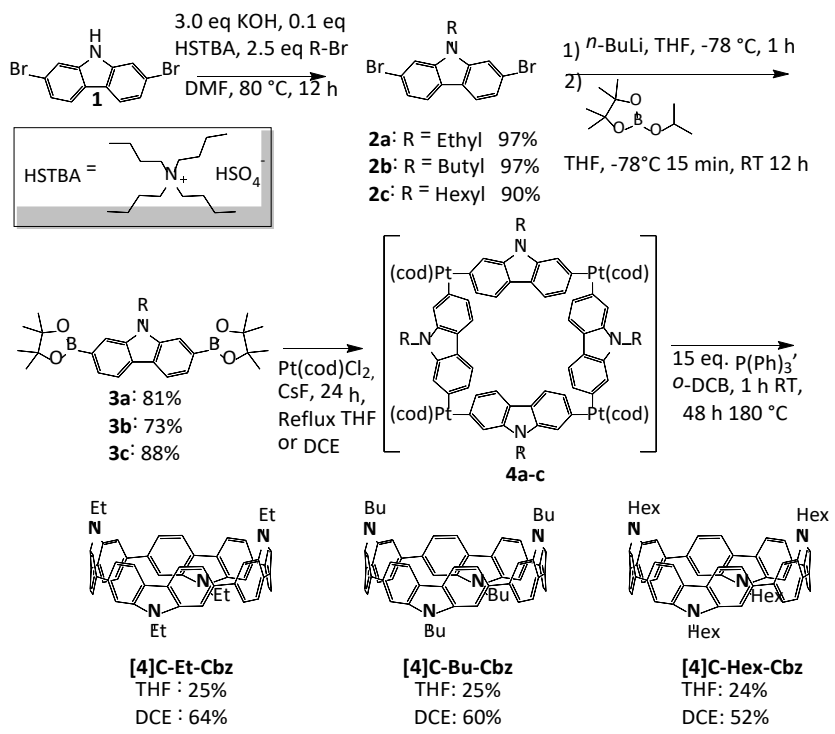

Scheme 1. Synthesis of [4]cyclo- $N$-alkyl-2,7-carbazoles: [4]C-Et-Cbz, [4]C-Bu-Cbz and [4]C-Hex-Cbz.

[4]C-Et-Cbz, [4]C-Bu-Cbz and [4]C-Hex-CBz were synthesized following the 'Pt approach' initially developed by Yamago and coworkers in $2010^{40}$ (Scheme 1). In a first attempt, [4]C-Et-Cbz was obtained with a relatively low yield of $6 \%$ from the bis(pinacolato)diboron carbazole $3 \mathbf{a}$ in two steps: i) the transmetallation step $\left(\mathrm{Pt}(\mathrm{cod}) \mathrm{Cl}_{2} / \mathrm{CsF}\right.$ at the reflux of THF for $24 \mathrm{~h}$ ) to form the tetraplatinum intermediate $\mathbf{4 a}$, followed by ii) the reductive elimination step $\left(\mathrm{P}(\mathrm{Ph})_{3}\right.$ in toluene $30 \mathrm{~min}$ at room temperature and then $24 \mathrm{~h}$ at the reflux). First, the reductive elimination step has been studied. Switching from the reflux of toluene to the reflux of $o$ dichlorobenzene (o-DCB) and from 24 to $48 \mathrm{~h}$ allow to significantly improve the yield from $6 \%$ to $25 \%$ (see Table S1). Isobe and coworkers have previously noted the positive impact of $o$-DCB on the reaction yield in the case of cyclonaphthylene nanohoops. ${ }^{41}$ Since the reductive elimination step is unfavoured by the strain energy, it can be helped by increasing both the temperature and reaction time. These conditions have been applied to the two other nanorings investigated herein and have allowed to isolate both [4]C-Bu$\mathbf{C b z}$ (from 3b) and [4]C-Hex-CBz (from 3c) with identical yields (ca $25 / 24 \%$ ). This not only shows the versatility of these experimental conditions but also highlights that the alkyl chain length does not have any impact on the reaction yield. A different result has been recently reported for structurally related fluorene nanorings, for which the alkyl chain borne by the bridge has a significant impact on the reaction yield. ${ }^{14}$

The transmetallation step has also been studied as a function of the reaction solvent. In the above mentioned experimental conditions, THF was used, as commonly found in literature. Herein, four other solvents (with a different polarity) have been studied for [4]C-Bu-Cbz, namely dimethylformamide (DMF), 1,1,2,2-tetrachloroethane (TCE), carbon tetrachloride $\left(\mathrm{CCl}_{4}\right)$ and 1,2-dichloroethane (DCE). Keeping the optimized elimination step described above $\left(o-\mathrm{DCB}, 180^{\circ} \mathrm{C}, 48 \mathrm{~h}\right)$, the yields appeared to be drastically different. Both $\mathrm{CCl}_{4}$ and TCE led to very low yield below $1 \%$, whereas DMF provided a 
modest yield of 9\%. Remarkably, DCE provided a very high yield of $60 \%$. It is clear that this reaction is highly sensitive to the characteristics of the solvent used (boiling point, polarity etc...) but the link between the different parameters is not unraveled to date. Additional mechanistic studies should be performed to finely investigate these solvent effects, which are undoubtedly crucial in this approach.

Finally, the three nanorings [4]C-Et-Cbz, [4]C-Bu-Cbz and [4]C-Hex-Cbz were synthesized using these optimized conditions in $64 \%, 60 \%$ and $52 \%$ yield respectively from their corresponding bis(pinacolato)diboron carbazole derivatives (i. Pt(cod) $\mathrm{Cl}_{2} / \mathrm{CsF}$ in DCE at $70^{\circ} \mathrm{C}$ for $24 \mathrm{~h}$, ii. $\left(\mathrm{P}(\mathrm{Ph})_{3}\right.$ in $o^{-}$ $\mathrm{DCB}$ at RT for $1 \mathrm{~h}$ and at $180^{\circ} \mathrm{C}$ for $48 \mathrm{~h}$ ), giving an overall yield for the formation of the present [4]-cyclocarbazoles of ca $47 \%$ from $\mathbf{2 a}, \mathbf{2 b}$ and $\mathbf{2 c}$, corresponding to an eightfold increase as compared to the protocol described by Yamago and coworkers via a distanylated carbazole (yield of $6 \%$ from the dibrominated precusor). ${ }^{39}$ This high yield procedure is promising and represents a first important step in order to reach sufficient amounts of [4]-cyclocarbazoles for incorporation in electronic devices.

\subsection{Structural Properties}

Molecular Structures of [4]C-Et-Cbz (CCDC 1893079), [4]C-Bu-Cbz (CCDC 2055214) and [4]C-Hex-Cbz (CCDC 2055215) were revealed by $X$-ray diffraction on single crystals (Figure 1). The three carbazole nanorings reveal the alternated $\alpha \beta \alpha \beta$ conformation in accordance with the NMR data (See figure S1-6). This conformation is consistent with that obtained with other bridged-CPPs. ${ }^{14,23,36}$
[4]C-Et-Cbz

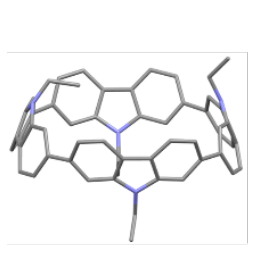

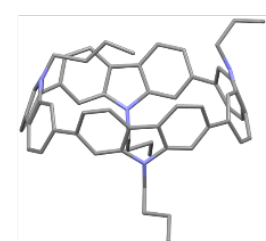

[4]C-Bu-Cbz

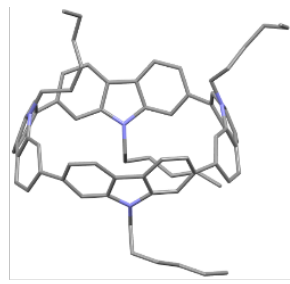

[4]C-Hex-Cbz

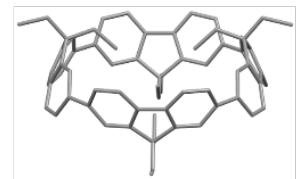

[4]C-diEt-F

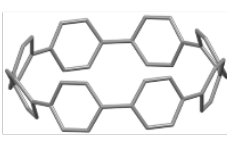

[8]CPP
Figure 1. Single crystal structures of [4]-cyclocarbazoles and of their related analogues [8]CPP (CCDC 871414) and carbon-bridged [4]C-diEt-F (CCDC 1580867).

Single crystals of [4]C-Et-Cbz and [4]C-Hex-Cbz were obtained by vapor diffusion of hexane in concentrated solution of chloroform, while for [4]C-Bu-Cbz they were obtained from hot saturated solution of toluene. [4]C-Et-Cbz, [4]C-Bu-Cbz and [4]C-Hex-Cbz crystallize in C2/C, $P 2{ }_{1}{ }_{2}{ }_{1} 2_{1}$ and $\mathrm{Cm}$ space groups respectively (see $\mathrm{X}$-ray diffraction tables in SI). [4]C-Et-Cbz crystallizes with a molecule of chloroform outside of the nanoring cavity, with which there is no apparent interaction. [4]C-Bu-Cbz co-crystallise with two molecules of toluene one trapped into its cavity and the other outside, implying that there are some interactions occurring.

Since the main factors regarding the origin of the specific electronic properties of the nanorings are the deformation of the constituting units and their relative arrangement, three structural parameters should be considered: the cavity axes and the mean diameter $\varnothing$, the mean torsion angle $\theta$ and the mean displacement angle $\omega$ (see definitions and detailed calculations in SI).

[4]C-Et-Cbz, [4]C-Bu-Cbz and [4]C-Hex-Cbz possess a mean diameter of ca $10.9 \AA$, with minimal C-C axes of 10.5 , 10.7 and $10.5 \AA$ respectively, and, maximal C-C axes of 11.2 $\AA$ for [4]C-Et-Cbz and [4]C-Hex-Cbz and $11.1 \AA$ for [4]CBu-Cbz (Table 1, Figure S7), thus forming less distorted ellipsoidal nanorings than [8]CPP (minimal C-C axis of 10.3 $\AA$ and maximal C-C axis of $11.7 \AA$ ). [4]C-diEt-F forms a perfect cylinder with a diameter of $11.0 \AA$ (Figure 1 and S7). Going from [8]CPP to [4]C-Et-Cbz, a decrease in the maximal C-C axis is induced, whereas an increase in the minimal C-C axis (to a lesser extent) is observed. This is related to shorter biphenyl bonds on average for [4]C-Et-Cbz (1.46 $\AA$ ) than for [8]CPP (1.49 A), Figure S8. However, when comparing [4]C-Et-Cbz and [4]C-diEt-F, nitrogen bridges do not generate a perfect cylinder in contrast to carbon bridges, as a result of the substitution of the bridge. Indeed, in the case of [4]C-diEt-F, it has been shown that there are four among the eight alkyl chains which are directed towards the centre of the cavity and which drive the shape of the ring. ${ }^{23} \mathrm{In}$ [4]C-Et-Cbz, the pyramidal nitrogen bridges lead to a different situation, with only one chain diving within the ring, leading therefore to a distorted ring. As we will see below, this structural characteristic has an impact on the photophysical properties. Finally, increasing the alkyl chain length borne by the nitrogen bridges does not significantly impact the shape of the carbazole nanoring.

In nanoring chemistry, the mean torsion angle $\theta$ between adjacent carbazole rings is an important parameter driving the electronic properties. [4]C-Et-Cbz, [4]C-Bu-Cbz and [4]C-

Hex-Cbz present a $\theta$ of $20.7^{\circ}, 19.0^{\circ}$ and $20.3^{\circ}$ respectively whereas those of [8]CPP and [4]C-diEt-F are recorded at 24.3 and $20.8^{\circ}$ respectively (Table 1 ). Thus, bridging [8]CPP with nitrogen ([4]C-Et-Cbz) or carbon atoms ([4]C-diEt-F) leads to a similar decrease of $\theta$, i.e. by $3.6^{\circ}$ and $3.5^{\circ}$ respectively. This shows that $\theta$ is more impacted by the presence of bridges than by their nature. The alkyl chain length has also an impact on $\theta$. The smallest was found for [4]C-Bu-Cbz and the largest for [4]C-Et-Cbz. At first glance, this behavior (the largest $\theta$ observed for the shortest chain) may be surprising, but the same was observed for 4cyclofluorenes, ${ }^{14,} 23,32$ and assigned to steric hindrance of alkyl chains that forces the alignment of the constituting units. 


\section{[4]C-Hex-Cbz}
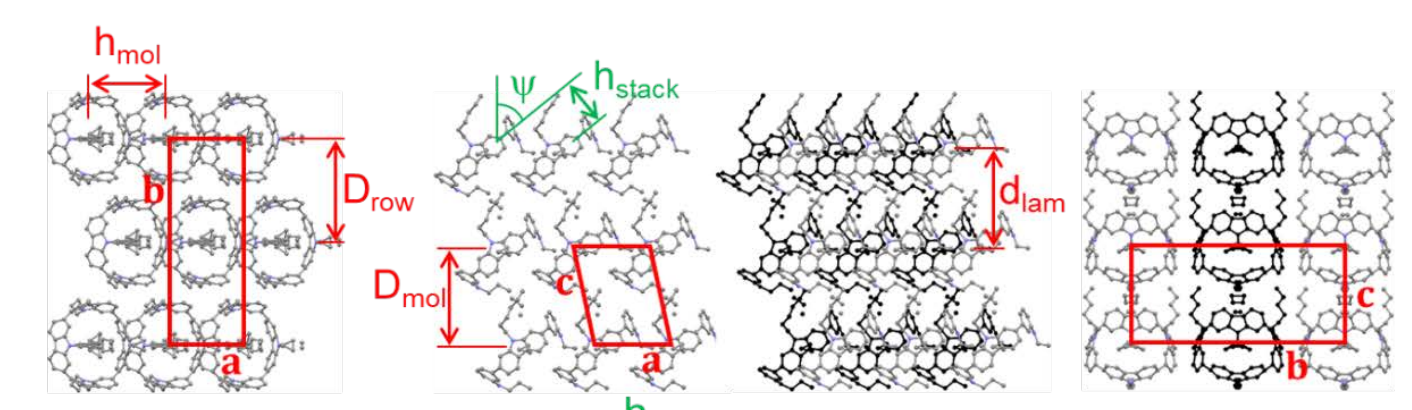

[4]C-Et-Cbz
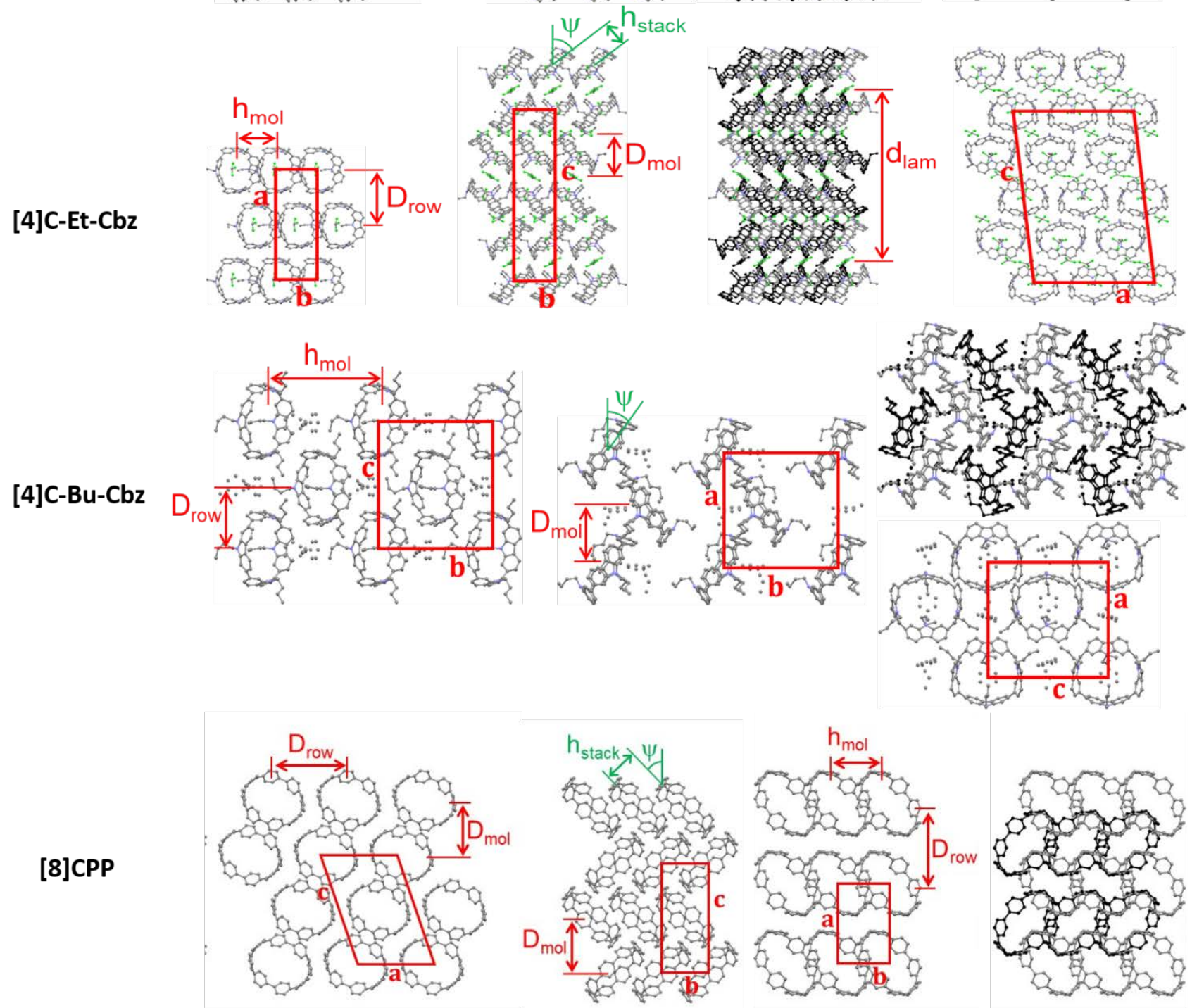

Figure 2. Views of the single-crystal structure of : [4]C-Hex-Cbz. from left to right, view along $c$-axis, $b$-axis (molecular slice at y $=0.0$ ), $b$-axis (with molecular slice in background drawn in black, $\mathrm{y}=0.5$ ), and $a$-axis (with the molecules in background drawn in black, $\mathrm{x}=0.5$ ); [4]C-Et-Cbz, from left to right, view along $c$-axis (molecular slice at $\mathrm{z}=0.15$ ), $a$-axis (molecular slice from $\mathrm{x}=0.0$ to $\mathrm{x}=0.5$ (molecules with centroids at $\mathrm{x}=0.15$ and $\mathrm{x}=0.35$ ), $a$-axis (entire cell with molecular slice in background drawn in black, $\mathrm{x}=0.5$ to 1.0 ), and $b$-axis; [4]C-Bu-Cbz, from left to right: view along $a$-axis (molecular slice at $\mathrm{x}=0.0$ ), $c$-axis (molecular slice at $\mathrm{z}=0.0$ ), $c$-axis (with molecular slice in background drawn in black, $\mathrm{z}=0.5$ ), and along $b$-axis (molecular slice at $\mathrm{y}=0.0$ ). [8]CPP ${ }^{42}$ From left to right: view along c-axis of the molecular layer at $\mathrm{z}=0.0$, view along $c$-axis of entire cell with molecular layer in background $(\mathrm{z}=0.5)$ drawn in black, view along $a$ axis, view along $b$-axis.

In the case of [4]C-Bu-Cbz, the toluene molecules lying inside and outside the cavity might induce even more steric hindrance than in the case of the longer hexyl chains, leading to a smaller $\theta$ than for [4]C-Hex-Cbz and [4]C-Et-Cbz. Nevertheless, calculated strain energies appear very similar (ca 72-73 kcal.mol ${ }^{-1}$ for [4]C-Et-Cbz, [4]C-Bu-Cbz and [4]C-Hex-Cbz) and almost identical to those of [8]CPP ${ }^{43}$ and [4]C-diEt-F ${ }^{23}$ (72 kcal.mol $\left.{ }^{-1}\right)$. This points to the little impact of the nature and the substitution of bridges and indicates that only the number of phenyl rings ( 8 for the nanorings considered in this study) is determining. ${ }^{43}$

[4]C-Et-Cbz, [4]C-Bu-Cbz and [4]C-Hex-Cbz display a mean displacement angle $\omega$ of $7.2^{\circ}, 7.1^{\circ}$ and $7.0^{\circ}$ respectively, and, [8]CPP and [4]C-diEt-F of $9.6^{\circ}$ and $6.9^{\circ}$ respectively (Table 1). Thus, we observe that bridging [8]CPP with nitrogen or carbon atoms leads to a decrease of $\omega$ linked to a 
planarisation of the biphenyl units. In summary, only the presence of the bridges (rather than their nature) affects $\omega$. Furthermore, the substitution of bridges does not have a significant impact on $\omega$.

Before any electronic application, studying the thermal and morphological stabilities is a mandatory step. As far as we are aware, such data have never been recorded for a nanoring to date (See TGA, DSC and POM in Figures S11-12, S14-15). TGA analysis of the three [4]-cyclocarbazoles revealed a very high thermal stability, with their 5\% weight loss temperature degradation $\left(\mathrm{T}_{5 \%}\right)$ lying in the $335-355^{\circ} \mathrm{C}$ interval. As observed by POM and DSC, the fine crystalline powders of [4]C-Et-Cbz and [4]C-Hex-Cbz do not show any phase transition on heating from room temperature onwards and up to degradation. After release of lattice solvent at $170^{\circ} \mathrm{C},[4] \mathrm{C}$ Bu-Cbz is also crystalline ( $\mathrm{Cr} 1$ form) and shows an irreversible, endothermic crystalline rearrangement in the first DSC run $\left(\mathrm{T}_{\text {onset }}=231^{\circ} \mathrm{C}, \Delta \mathrm{H}=12.4 \mathrm{~J} / \mathrm{g}\right)$; this new crystalline form, $\mathrm{Cr} 2$, is maintained on subsequent cooling/heating cycles up to degradation. For [8]CPP, weight loss from degradation starts around $350^{\circ} \mathrm{C}$ and reaches $5 \%$ at $420^{\circ} \mathrm{C}$, and DSC curves on heating and on cooling do not display any phase transition peak (Figure S11). In consistency with DSC/POM/TGA analysis, the three powder samples exhibit same crystal phase at $20^{\circ} \mathrm{C}$ and $180^{\circ} \mathrm{C}$, as that of [4]C-HexCbz, also identical to its single crystal phase at $-123^{\circ} \mathrm{C}$. [4]CEt-Cbz and [4]C-Bu-Cbz give different structures in single crystal and powder states, due to presence of lattice solvent in the single crystal structures and its absence in the crystalline powders analyzed by S/WAXS. Contrarily to the crude solvent-free [4]C-Et-Cbz powder, [4]C-Bu-Cbz powder initially contained lattice solvent that is released by annealing for a few minutes at $170^{\circ} \mathrm{C}$ prior to DSC and S/WAXS experiments.

Remarkably, S/WAXS patterns of [4]C-Hex-Cbz point to a well crystallized powder having the same crystalline structure as the single crystal form. The sharp reflections in the whole angular range authorized the accurate determination of the cell parameters as a function of temperature. In contrast, reflections collapse above $20-25^{\circ}$ for [4]C-Et-Cbz and [4]C$\mathbf{B u}-\mathbf{C b z}$, which reveals a high level of structural disorder and precluded structural resolution. Recrystallization of [8]CPP in dichloromethane was consistent with the single crystal pattern previously reported. ${ }^{42}$

It is interesting to note that the molecular volume, $\mathrm{V}_{\mathrm{mol}}$, increases linearly ([4]C-Et-Cbz $\rightarrow$ [4]C-Bu-Cbz $\rightarrow$ [4]CHex-Cbz) according to a volume contribution per methylene unit of $\mathrm{V}_{\mathrm{CH}_{2}}=24.40 \AA^{3}$ (Figure S13, Tables S5-6). This value is $8 \%$ above the lowest one reached in crystalline phases of linear n-alkanes $\left(\mathrm{V}_{\mathrm{CH}_{2}}=22.63 \AA^{3}\right.$ for decane at $-123^{\circ} \mathrm{C}$ in structure CSD-QQQFBG0). ${ }^{44}$ Such a substantial excess volume reflects chains with poorly stretched conformations that prevent their self-arrangement in compact crystalline slabs. Furthermore, extrapolation of the variation to $\mathrm{n}=0$ (i.e. no alkyl chain on nitrogen atoms) gives access to the partial volume of the ring moiety: $V_{\text {ring }}=901 \AA^{3}$ (Figure S13).

In the crystal phase, molecules of [4]C-Hex-Cbz (Figure 2) pile into rows with molecular spacing $\mathrm{h}_{\text {mol }}$ that juxtapose with spacing $\mathrm{D}_{\text {row }}$ into molecular layers of thickness $\mathrm{D}_{\text {mol }}$. Neighboring rows are shifted by $\mathrm{h}_{\mathrm{mol}} / 2$ and define a centered rectangular sublattice $\left(a_{2 \mathrm{D}}=b, b_{2 \mathrm{D}}=a\right.$, and $Z_{2 \mathrm{D}}=2$ rings per lattice). Nanoring moieties are tilted in the row direction (outof-plane tilt angle $\psi$ ), allowing them to stack over nearly half of their surface with stacking distance $\mathrm{h}_{\text {stack }}$ and to repel the alkyl substituents into the interlayers. The chains therefore merge into aliphatic layers alternating with stacked nanoring layers by forming a lamellar substructure of a single molecular layer periodicity $\mathrm{d}_{\mathrm{lam}}=\mathrm{D}_{\text {mol }}$. Successive molecular layers superimpose with a shift in the row direction resulting in an overall cell structure of monoclinic symmetry. The rows of piled nanorings correspond to a supramolecular selfassembly into hollow columns arranged in a lamellocolumnar structure, in which the equally tilted and vertically shifted columns alternate with aliphatic layers according to a primitive rectangular sublattice $\left(a_{\mathrm{col}}=b, b_{\mathrm{col}}=c, Z_{\mathrm{col}}=2\right.$ columns per lattice).

The self-assembly of nanoring [4]C-Et-Cbz (Figure 2) is similar to the hexyl counterpart [4]C-Hex-Cbz, in a centered rectangular in-plane arrangement $\left(a_{2 \mathrm{D}}=a, b_{2 \mathrm{D}}=b, Z_{2 \mathrm{D}}=2\right.$ rings per lattice). However, the interlayer zones are of different nature and modify the 3D structure. The formation of aliphatic layers is excluded for the short ethyl chains, which is probably the main reason for the presence of co-crystallized solvent molecules between molecular layers. This interstitial solvent removes the constrains associated to the attachment of aliphatic chains to the nanorings but introduces other constrains due to the fixed volume of solvent molecules. Specifically, the lamellar configuration is changed in a sequence of 4 molecular layers, in which couples of neighboring layers and solvent molecules associate in herringbone fashion in double-layers with opposite tilt directions of the rows. The lamellar periodicity involves two of such double-layers with inverted ring orientations that alternate with interstitial solvent strata. Due to rows inversion, the average longitudinal shift in the direction of rows is zero and implies a rectangular sub-arrangement in the $(b c)$ plane. At the same time, the incorporated solvent volume induces a laterally shifted positioning of successive molecular layers and an overall cell structure of monoclinic symmetry. Consequently, the hollow columns of piled nanorings form a lamello-columnar structure with an oblique lattice: $a_{\mathrm{col}}=c, b_{\mathrm{col}}$ $=a, Z_{\mathrm{col}}=8$ columns per lattice.

The structure of [4]C-Bu-Cbz$\cdot \mathbf{C}_{6} \mathbf{H}_{5} \mathbf{C H}_{3}$ (Figure 2) crystals keeps some features of [4]C-Hex-Cbz, in particular the layers aligned in staggered rows according to a rectangular in-plane arrangement ( $a_{2 \mathrm{D}}=c, b_{2 \mathrm{D}}=b, Z_{2 \mathrm{D}}=2$ molecules per lattice). However, the rows are swollen by the insertion of cocrystallized solvent between aligned molecules and the piling of ring is de facto suppressed. In addition, rows have lower section at solvent insertion zones, which is compensated by the partial intercalation of the neighboring rows and thus by the reduction of row spacing $D_{\text {row }}$ and molecular layer thickness $D_{\text {mol }}$. Nanorings are tilted to adapt the constrain of space filling and fixed molecular volume of solvent. Due to the tilt inversion from row to row, the arrangement in the molecular layer plane is not any more centered but primitive rectangular. For the same reason, the arrangements in the ab and $(a c)$ planes are also primitive rectangular with two molecules per sublattice, in consistency with the overall orthorhombic symmetry. The supramolecular structure annihilates the ring interactions and the self-assembly into hollow columns. 

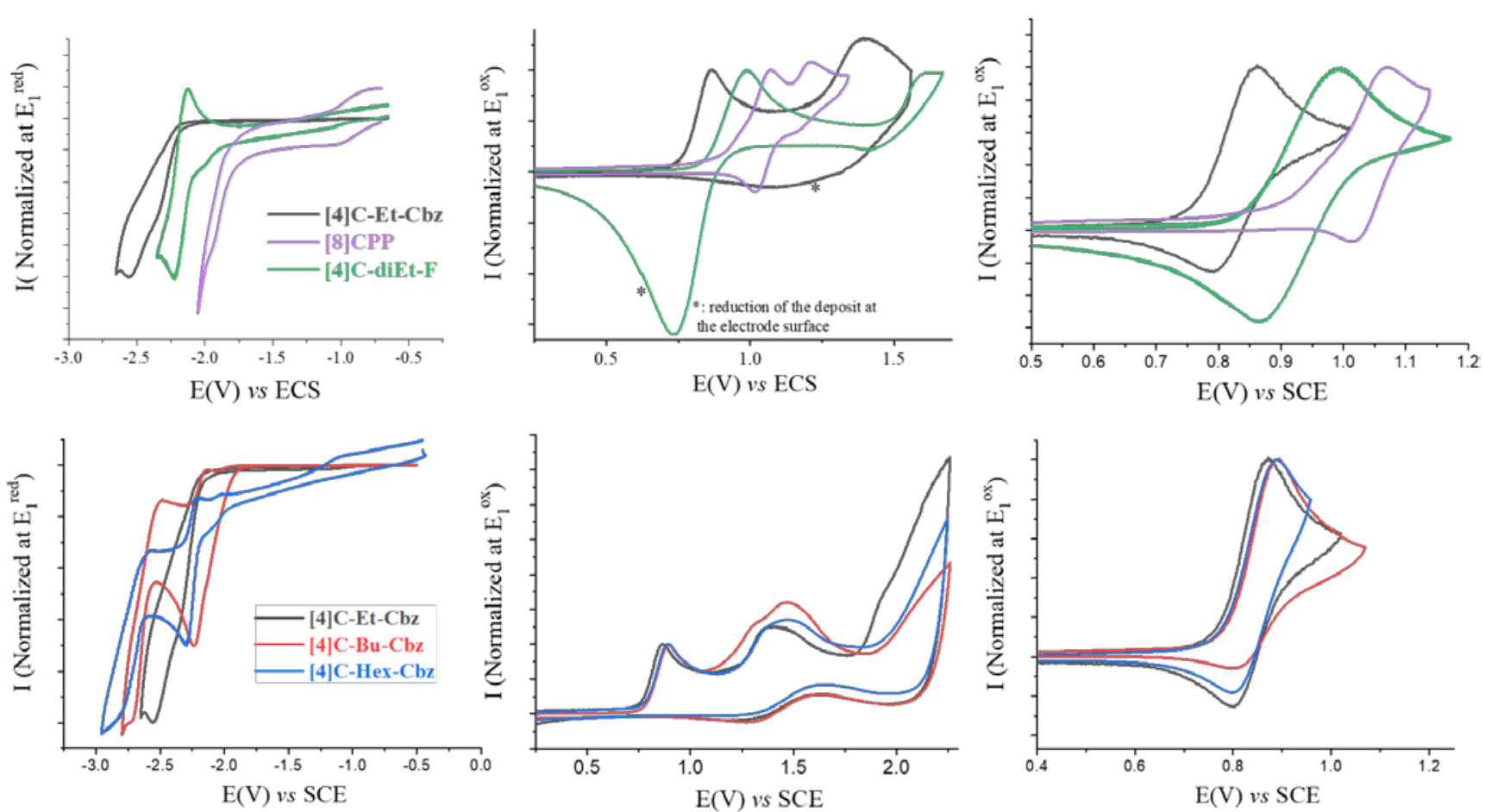

Figure 3. Cyclic Voltammograms of [8]CPP, [4]C-diEt-F and [4]-cyclocarbazoles $\left(2 \times 10^{-3} \mathrm{M}\right)$ in reduction $(\mathrm{Left})$ in $\mathrm{DMF}\left(\mathrm{Bu}_{4} \mathrm{NPF}\right.$, $0.1 \mathrm{M})$ and in oxidation (Middle and Right) in $\mathrm{CH}_{2} \mathrm{Cl}_{2}\left(\mathrm{Bu}_{4} \mathrm{NPF}_{6}, 0.2 \mathrm{M}\right)$. Platinum working electrode, sweep rate $100 \mathrm{mV} / \mathrm{s}$.

The molecular organization of [8]CPP (Figure 2) is analogue to that of [4]C-Et-Cbz and [4]C-Hex-Cbz. However, these structural features are modified since the arrangement of the cyclocarbazole nanorings is constrained by the rejection of the alkyl substituents in the interlayers, whereas that of [8]CPP reflects the optimal ring interactions and packing. Specifically, the carbazole nanorings are constrained by substituents to be tilted toward layer boundaries and a staggered juxtaposition of rows is needed for their compact interlocking; these constrains vanish for [8]CPP and rows orient with an in-plane component of tilt realizing the interlocking with the neighboring rows. As a consequence, the in-plane arrangement changes from centered rectangular with 2 molecules per lattice to primitive rectangular with 1 molecule per lattice $\left(a_{2 \mathrm{D}}=a, b_{2 \mathrm{D}}=b\right)$. Successive molecular layers have shifted positioning and reversed tilt orientation defining a cell periodicity of two molecular layers and the monoclinic symmetry. There is no alternation with substituent layers and therefore no lamellar substructure; the arrangement of [8]CPP rows defines a columnar structure of herringbonetilted hollow columns (2 columns with inverted tilt orientations per oblique sublattice of parameters: $a_{2 \mathrm{D}}{ }_{2 \mathrm{D}}=c, b_{2 \mathrm{D}}$ $=a, \mathrm{~g}_{2 \mathrm{D}}=\mathrm{b}$ ).

In addition, the mean cross-sectional areas $\left(\sigma_{\text {ring }}\right)$ including molecular gaps are ca. $154 \AA^{2}$ for [4]-cyclocarbazoles and ca $167 \AA^{2}$ for [8]CPP, corresponding to equivalent hard-cylinder diameters ( $\left.\mathrm{D}_{\text {ring, cyl }}\right)$ of 13.4 and $13.9 \AA$ (Table S5). [4]C-HexCbz, [4]C-Et-Cbz and [8]CPP give rise to self-association of rings into tilted, hollow columns. The stacking distance $\left(\mathrm{h}_{\text {stack }}\right)$ is $5.8 \AA$ in all cases (Table S6) and the tilt angle ( $\psi)$ is larger for the [4]-cyclocarbazoles due to the space-requirement of substituents $\left(\approx 51^{\circ}\right.$ compared to $44^{\circ}$ for [8]CPP). Corollary, the tilting reduces the internal cross-section ( $\mathrm{S}_{\text {ring }}$ ) of columns to $96-98 \AA^{2}$ and $\approx 104 \AA^{2}$, respectively.
Finally, [4]C-Bu-Cbz stands out in this series since no lamello-columnar structure could be obtained for this compound. In fact, some crystal growth trials yielded a structure swollen with co-crystallized toluene, [4]C-Bu$\mathbf{C b z} \cdot \mathbf{C}_{6} \mathbf{H}_{5} \mathbf{C H}_{3}$, in which solvent molecules insert between nanorings, hence interrupting interactions and therefore erasing the supramolecular assembly. Tentatively, we propose that this swollen structure appears because of the volume of the butyl chain that is neither able to fill up the voids in the lamello-structure structure nor to leave sufficient space for the insertion of solvent molecules. For the solvent-free systems ([4]C-Hex-Cbz and [8]CPP), the supramolecular structures are maintained in the powder state. The effect of thermal expansion on lamello-columnar structures was scrutinized for [4]C-Hex-Cbz and revealed a marginal shrinkage between $20^{\circ} \mathrm{C}$ and $-123^{\circ} \mathrm{C}$, meaning that the structure freezes close to room temperature. Between $20^{\circ} \mathrm{C}$ and $180^{\circ} \mathrm{C}$, the volume expansion is $2.4 \times 10^{-4 \circ} \mathrm{C}^{-1}$ with balanced contributions of row spacing $\mathrm{D}_{\text {row }}\left(1.3 \times 10^{-4 \circ} \mathrm{C}^{-1}\right)$ and lamellar periodicity $\mathrm{d}_{\text {lam }}$ $\left(0.9 \times 10^{-4 \circ} \mathrm{C}^{-1}\right)$, while periodicity along columns $\mathrm{h}_{\text {mol }}$ is nearly constant $\left(0.1 \times 10^{-4 \circ} \mathrm{C}^{-1}\right)$. Therefore, thermal expansion essentially affects the spacing of columns in a comparable way along all directions of the columnar plane.

\subsection{Electrochemical Properties}

Electrochemical properties of the five nanorings were determined by cyclic voltammetry in strictly identical conditions. [8]CPP, [4]C-diEt-F and [4]C-Et-Cbz present very different cyclic voltammograms (CVs, Figure 3 top). [4]C-Et-Cbz displays, between 0 and $1.5 \mathrm{~V}$, two oxidation waves with maxima at 0.86 and $1.40 \mathrm{~V}$ (Figure 3 and Table 1). Similarly, [8]CPP also presents two oxidation waves with peak potentials recorded at 1.07 and 1.22 V. Finally, [4]CdiEt-F displays two irreversible waves with maxima recorded at 0.99 and $1.60 \mathrm{~V}$. 
Table 1. Electrochemical properties, frontier molecular energies, structural parameters $\varnothing, \omega$ and $\theta$ of [8]CPP, [4]C-diEt-F, [4]C-EtCbz, [4]C-Bu-Cbz, and [4]C-Hex-Cbz. Potentials are given vs SCE.

\begin{tabular}{|c|c|c|c|c|c|}
\hline & [8]CPP & [4]C-diEt-F & [4]C-Et-Cbz & [4]C-Bu-Cbz & [4]C-Hex-Cbz \\
\hline & \multicolumn{5}{|c|}{ Electrochemical data } \\
\hline$E^{o x}(V)$ & $1.07 ; 1.22$ & $0.99 ; 1.60$ & $0.86 ; 1.40 ; 2.03^{*}$ & $\begin{array}{c}0.89 ; 1.3 * ; 1.47 ; \\
>1.80\end{array}$ & $0.89 ; 1.36^{*} ; 1.53$ \\
\hline$E_{\text {onset }}{ }^{o x}(V)$ & 0.88 & 0.83 & 0.77 & 0.78 & 0.79 \\
\hline$H_{O M O}^{a}(e V)$ & -5.28 & -5.23 & -5.17 & -5.18 & -5.19 \\
\hline$E^{r e d}(V)$ & $-1.94 *$ & $-2.00 * ;-2.23$ & $-2.30 * ;-2.52$ & $-2.23 ;-2.70^{*}$ & $-2.30 ;-2.83$ \\
\hline$E_{\text {onset }}^{\text {red }}$ & -1.80 & -2.06 & -2.18 & -2.00 & -2.19 \\
\hline \multirow[t]{2}{*}{$L U M O^{a}(e V)$} & -2.60 & -2.34 & -2.22 & -2.40 & -2.21 \\
\hline & \multicolumn{5}{|c|}{ Structural data } \\
\hline $\begin{array}{c}\varnothing(\AA) \\
{[\min -\max ]}\end{array}$ & $\begin{array}{c}11.1 \\
{[10.3-11.7]}\end{array}$ & $\begin{array}{c}11.0 \\
{[11.0-11.0]}\end{array}$ & $\begin{array}{c}10.8 \\
{[10.5-11.2]}\end{array}$ & $\begin{array}{c}10.9 \\
{[10.7-11.1]}\end{array}$ & $\begin{array}{c}10.9 \\
{[10.5-11.2]}\end{array}$ \\
\hline $\begin{array}{c}\theta\left({ }^{\circ}\right) \\
{[\min -\max ]}\end{array}$ & $\begin{array}{c}24.3 \\
{[1.46-42.5]}\end{array}$ & $\begin{array}{c}20.8 \\
{[0.0-41.5]}\end{array}$ & $\begin{array}{c}20.7 \\
{[19.4-22.0]}\end{array}$ & $\begin{array}{c}19.0 \\
{[17.3-21.1]}\end{array}$ & $\begin{array}{c}20.3 \\
{[19.9-22.5]}\end{array}$ \\
\hline $\begin{array}{c}\omega\left(^{\circ}\right) \\
{[\min -\max ]}\end{array}$ & $\begin{array}{c}9.6 \\
{[7.2-11.4]}\end{array}$ & $\begin{array}{c}6.9 \\
{[6.4-7.4]}\end{array}$ & $\begin{array}{c}7.2 \\
{[6.5-8.2]}\end{array}$ & $\begin{array}{c}7.1 \\
{[6.2-8.3]}\end{array}$ & $\begin{array}{l}7.0 \\
{[6.1-7.8]}\end{array}$ \\
\hline
\end{tabular}

* shoulder, a. HOMO/LUMO energy levels have been calculated from electrochemical data as follows HOMO = - [4.4 + $\mathrm{E}_{\text {onset }}{ }^{\text {ox }}(\mathrm{V}$ vs SCE)] and LUMO = -[4.4 + $\mathrm{E}_{\text {onset }}^{\text {red }}(\mathrm{V}$ vs SCE) $]$.

Note that the first wave appears reversible for all compounds at a sweep rate of $100 \mathrm{mV} / \mathrm{s}$ (Figure 3 top right). Thus, the lowest oxidation potential is detected for [4]C-Et-Cbz followed by [4]C-diEt-F and by [8]CPP.

HOMO energy levels, calculated from onset oxidation potentials ( $\mathrm{E}_{\text {onset }}$ ox , Table 1 ) were respectively evaluated at -5.17, -5.23 and $-5.28 \mathrm{eV}$ for [4]C-Et-Cbz, [4]C-diEt-F and [8]CPP. Thus, the presence of the bridge and its nature (C vs $\mathrm{N}$ ) impact the HOMO energy level. The increase of the HOMO level going from [8]CPP to [4]C-diEt-F is readily explained by the increased degree of conjugation imposed by the bridging units which reduces the torsion angle between the connected phenyl units. The additional upward shift of the HOMO in the tetracarbazole derivatives is associated to the higher electron rich (electron-donating) character of the carbazole building unit. It is important to stress out that the HOMO trend detected for the three nanorings is the same as their constituting units: $N$-ethylcarbazole (HOMO $=-5.52$ $\mathrm{eV})^{45}$ presents a higher HOMO energy level than 9,9'diethylfluorene $(\mathrm{HOMO}=-5.71 \mathrm{eV})^{46}$ and biphenyl $(\mathrm{HOMO}=-6.15 \mathrm{eV}) .^{47}$ This confirms that the HOMO energy levels of the nanorings are controlled by their building units. We will see below that all properties do not follow this rule, e.g. absorption spectroscopy.

Let us have a look now at the effect of the alkyl chain length borne by the nitrogen atoms on the electrochemical properties. At a first glance, the three [4]-cyclocarbazoles present, in oxidation, very similar CVs with a first quasi reversible oxidation wave at ca $0.9 \mathrm{~V}(0.86 \mathrm{~V}$ for [4]C-Et-Cbz and 0.89 $\mathrm{V}$ for both [4]C-Bu-Cbz and [4]C-Hex-Cbz) followed by two other waves between 1.2 and 2.1 V. HOMO energy levels were evaluated at $-5.17 \mathrm{eV}$ for [4]C-Et-Cbz, $-5.18 \mathrm{eV}$ for [4]C-Bu-Cbz and $-5.19 \mathrm{eV}$ for [4]C-Hex-Cbz. Thus, the alkyl chain slightly modifies the first oxidation potential of the nanorings, as typically observed for $\pi$-conjugated systems. This evolution is rationalized by the stronger inductive effect of the ethyl group compared to butyl or hexyl, which slightly shifts towards lower values the first oxidation potential. A similar result has already been observed in literature for carbazole itself. ${ }^{48-49}$ Another characteristic of the [4]cyclocarbazoles is their ability to polymerize at the electrode surface as frequently observed for many linear $\pi$-systems. ${ }^{50-52}$ This behavior has recently been approached in literature ${ }^{23,36}$ and will not be discussed here. CVs showing the electropolymerization processes are provided in Figures S15-16.

In reduction, [4]C-Et-Cbz, [4]C-Bu-Cbz and [4]C-Hex-Cbz display two irreversible reduction processes at $-2.30(\mathrm{sh}) /-$ 2.52, $-2.23 /-2.70$ and $-2.30 /-2.83 \mathrm{~V}$ respectively (Figure 3 left). These potential values are significantly lower than those of [8]CPP, -1.94 V, signing the strong impact of the nitrogen atoms on the reduction processes. The LUMO are hence evaluated at ca $-2.40 \mathrm{eV}$ for [4]C-Bu-Cbz and -2.22/-2.21 eV for [4]C-Et-Cbz/[4]C-Hex-Cbz respectively and appear significantly higher than that of [8]CPP $(-2.60 \mathrm{eV})$, Table 1. This is caused once again by the electron-rich character of the carbazole building block. In this series, one can note that [4]C-Bu-Cbz displays the lowest LUMO and the smallest $\theta$, in accordance with an increase in the conjugation degree.

Finally, it is interesting to compare these cathocic explorations with those of the fluorene analogue [4]C-diEt-F, which displays a reversible wave centred at $-2.23 \mathrm{~V}$ ([4]C-EtCbz displays an irreversible wave), leading to a LUMO energy level of $-2.34 \mathrm{eV}$, lower than that of [4]C-Et-Cbz. This is in accordance with the more electron rich character of carbazole vs fluorene and with the HOMO evolution detailed above (HOMO of [4]C-Et-Cbz is higher than that of [4]CdiEt-F). Altogether, the trend is the following: $\mathrm{LUMO}([4] \mathrm{C}$ Et-Cbz) > LUMO([4]C-diEt-F) > LUMO([8]CPP)). This shows that the nature of the bridge ( $\mathrm{N} v \mathrm{C}$ ) influences not only the reduction potential but also the stability of the resulting radical anion. 

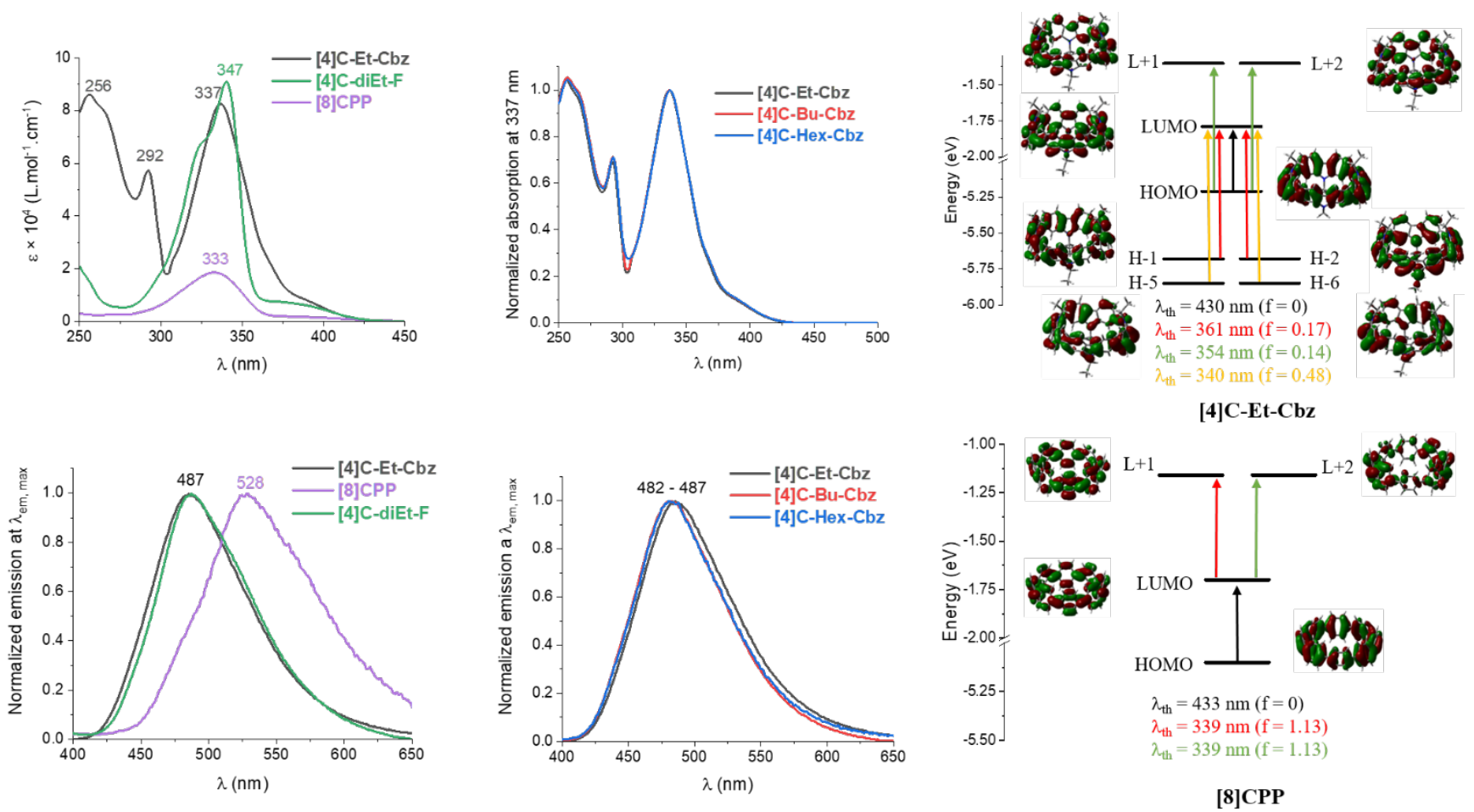

Figure 4. Left and Middle: Absorption (Top) and Emission (Bottom, $\lambda$ exc = $340 \mathrm{~nm}$ ) spectra of [8]CPP, [4]C-diEt-F and [4]cyclocarbazoles in cyclohexane. Right. Representation of the energy levels and the main molecular orbitals involved in the electronic transitions of [4]-Et-Cbz and [8]CPP, as obtained by TD-DFT, B3LYP/6-311 + G(d,p), shown with an isovalue of 0.02 [e bohr$3] 1 / 2$. For clarity purpose, only the major contribution of each transition is shown.

\subsection{Photophysical Properties}

The optical properties were characterized by UV/visible absorption spectroscopy as well as stationary and timeresolved fluorescence (Figure 4). The absorption spectra of the three [4]-cyclocarbazoles in cyclohexane are almost superimposable with three main bands at 256/257 nm, 292/293 nm and $337 \mathrm{~nm}$, Figure 4 top left. The classical band tail is also detected at around $400 \mathrm{~nm}$. This band is assigned, according to time-dependent density functional theory (TDDFT) calculations (Figure 4 and S26-27), to a symmetry forbidden ( $f=0$ ) HOMO $\rightarrow$ LUMO transition due to the Laporte rules (See HOMO/LUMO distribution in Figure S30). These calculations also show that the three [4]cyclocarbazoles display an identical behavior, with the same transitions involved (see diagrams in Figures S25-26). Thus, the different substitutions of the nitrogen atom have a negligible impact on the absorption characteristics in solution and the corresponding molecular orbitals involved.

The main band at $337 \mathrm{~nm}$ is due to six transitions (almost degenerated two by two): HOMO-5 $\rightarrow$ LUMO and HOMO$6 \rightarrow$ LUMO $(\lambda$ th $=340 \mathrm{~nm}), \mathrm{HOMO} \rightarrow \mathrm{L}+1$ and $\mathrm{HOMO} \rightarrow \mathrm{L}+2$ $(\lambda$ th $=354 \mathrm{~nm})$, and HOMO-1 $\rightarrow$ LUMO and HOMO$2 \rightarrow \operatorname{LUMO}(\lambda$ th $=361 / 362 \mathrm{~nm}$ ); the latter are responsible for the shoulders at around 370 and $385 \mathrm{~nm}$ in the experimental absorption spectra. The HOMO density in the three [4]cyclocarbazoles is similar to that in [8]CPP, ${ }^{7,28}$ and [4]CdiEt-F (See Figure S30) with no participation of the nitrogen atoms (as LUMO+1 and LUMO+2 orbitals), whereas the LUMO density resembles that of carbazole Cbz (Figure S30), with no participation of the carbon atoms at C3/C6. For the other orbitals involved (HOMO-6, HOMO-5, HOMO-2 and HOMO-1), the nitrogen atoms participate to the electronic delocalization.
The energy band found at $337 \mathrm{~nm}$ for [4]C-Et-Cbz $(\varepsilon=8.3$ $\left.\times 10^{4} \mathrm{~L} \cdot \mathrm{mol}^{-1} \cdot \mathrm{cm}^{-1}\right)$ and the tail at $400 \mathrm{~nm}$ are also found in both [8]CPP $\left(\lambda=333 \mathrm{~nm}, \varepsilon=1.9 \times 10^{4} \mathrm{~L} \cdot \mathrm{mol}^{-1} \cdot \mathrm{cm}^{-1}\right)$ and [4]C-diEt-F $\left(\lambda=347 \mathrm{~nm}, \varepsilon=9.1 \times 10^{4} \mathrm{~L} \cdot \mathrm{mol}^{-1} \cdot \mathrm{cm}^{-1}\right)$ and are therefore not dependent on the nature of the building unit but rather to the specific arrangement of the nanoring itself, in other words the radial geometry (Figure 4 top left). Nevertheless, it should be noted that the band at $337 \mathrm{~nm}$ of [4]C-Et-Cbz is due to 6 transitions, among which 2 are also found in [8]CPP and [4]C-diEt-F (HOMO $\rightarrow$ LUMO+1 and $\mathrm{HOMO} \rightarrow \mathrm{LUMO}+2$, without the participation of the nitrogen in these orbitals) and 4 specific to [4]-cyclocarbazoles (HOMO-5 $\rightarrow$ LUMO and HOMO-6 $\rightarrow$ LUMO, HOMO$1 \rightarrow$ LUMO and HOMO-2 $\rightarrow$ LUMO, with the nitrogen atoms involved in these orbitals). The latter couple explains why the [4]-cyclocarbazoles display a larger tail than [8]CPP and [4]C-diEt-F.

Moreover, the two higher-energy bands of the [4]cyclocarbazoles at 256/257 $\mathrm{nm}$ and 292/293 nm are absent from the spectra of [8]CPP and [4]C-diEt-F. These two bands are the signature of the carbazole unit as they are also found in $\mathbf{C b z}(\lambda=292$ and $255 \mathrm{~nm}$ in cyclohexane, Figure S20). To conclude, the low energy transitions ( $\lambda=337$ and $400 \mathrm{~nm})$ are specific to the nanoring itself (these bands are also found in many nanorings) whereas the high-energy transitions ( $\lambda=260$ and $290 \mathrm{~nm})$ and the shoulders $(\lambda=370$ and $385 \mathrm{~nm})$ are specific to the [4]-cyclocarbazoles. Thus, the impact of the unit, carbazole $v s$ fluorene, is different when comparing absorption and electrochemical properties. In electrochemistry, the carbazole mainly drives the properties whereas in absorption, the radial geometry is the driving force. 

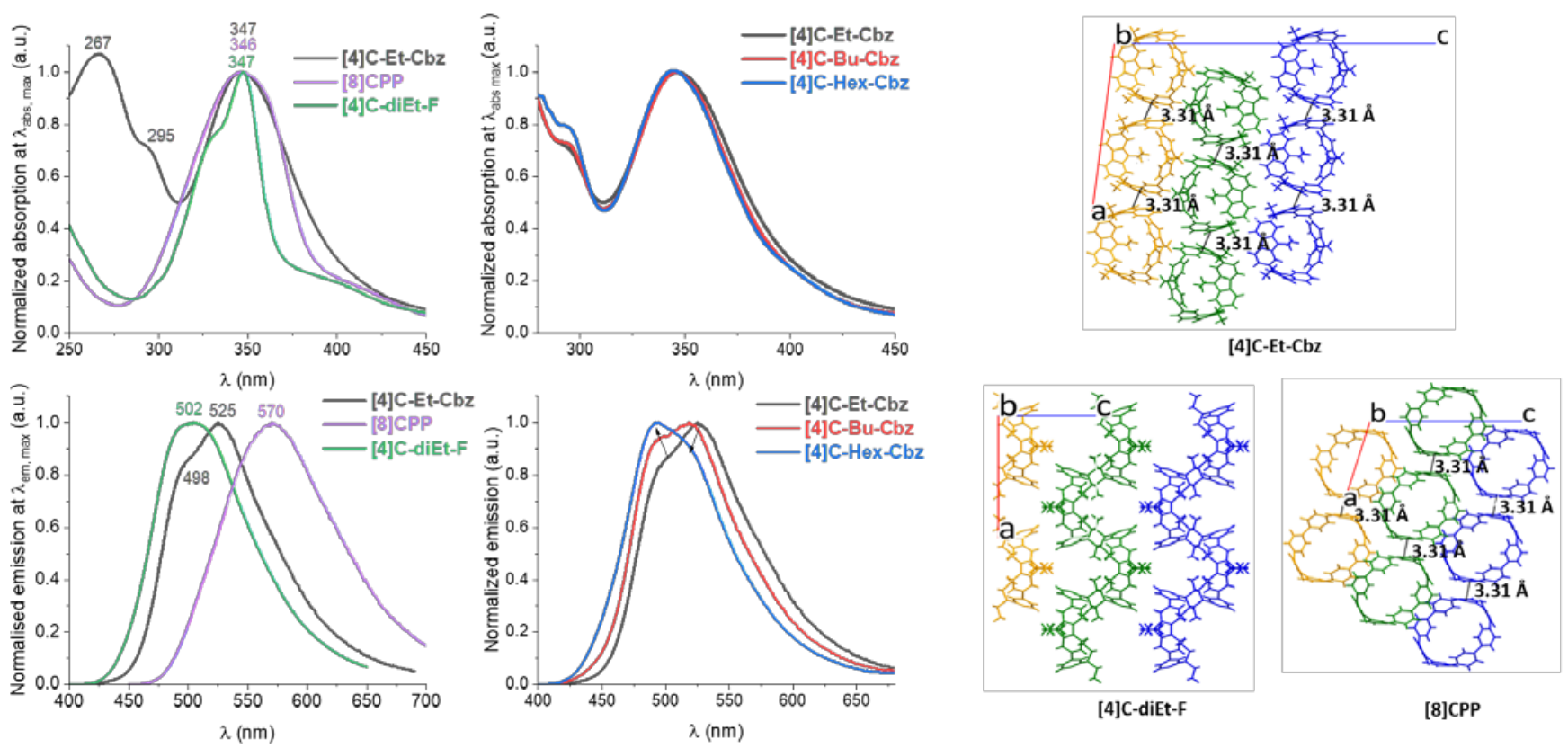

Figure 5. Left and Middle: Absorption spectra (Top) and Emission spectra (Bottom, $\lambda_{\text {exc }}=340 \mathrm{~nm}$ ) of [8]CPP, [4]C-diEt-F and [4]cyclocarbazoles in thin film. Right: Molecular packing of [8]CPP, [4]C-diEt-F and [4]C-Et-Cbz along the b axis.

In emission spectroscopy (Figure 4 bottom), the three [4]cyclocarbazoles display an almost identical unresolved spectrum with a maximum comprised between 482 and 487 $\mathrm{nm}$ (in cyclohexane). The full-width at half maximum (FWHM) is $80 \mathrm{~nm}$ for the three compounds. The efficiency of these green emitters is also the same with quantum yields of 0.2. Remarkably, the emission spectrum of [4]C-Et-Cbz almost overlaps with that of [4]C-diEt-F $\left(\lambda_{\max }=487 \mathrm{~nm}\right)$ and the quantum yield is also almost the same $(0.24)$. This highlights that the nature of the bridge has no influence on the emission properties, showing the importance of the radial geometry. Compared to [8]CPP $\left(\lambda_{\max }=528 \mathrm{~nm}\right)$, a strong hypsochromic shift of $41 \mathrm{~nm}$ is detected. Thus, the presence of a bridge linking two phenyl units leads to a significant blue shift of the fluorescence signal compared to that of nonbridged [8]CPP. Since the absorption spectra of [4]cyclocarbazoles and [8]CPP are similar, this induces a smaller Stokes shift in the formers than in the latter. This can be explained by a weaker rearrangement in the excited state for [4]C-Et-Cbz and [4]C-diEt-F due to the presence of the bridges. Note that the presence of the bridges does not impact the quantum yield which was evaluated at 0.25 for [8]CPP.

The fluorescence decay curve of the [4]-cyclocarbazoles $\left(\lambda_{\text {exc }}\right.$ $=310 \mathrm{~nm}$, Figure S21-24) provides a lifetime of 6.2, 6.2 and 6.3 ns for [4]C-Et-Cbz, [4]C-Bu-Cbz and [4]C-Hex-Cbz respectively, clearly indicating that the size of the alkyl chain does not affect this parameter. These lifetimes are shorter than that of [8]CPP measured at 10.6 ns in identical conditions, due to higher radiative and non-radiative constants (resp. $\mathrm{k}_{\mathrm{r}}$ and $k_{n r}$ ) for the [4]-cyclocarbazoles. The $k_{\mathrm{r}}$ of [4]cyclocarbazoles are calculated to be ca 3.1/3.2 $\times 10^{7} \mathrm{~s}^{-1}$ and are only slightly higher than that of [8]CPP $\left(2.4 \times 10^{7} \mathrm{~s}^{-1}\right)$ whereas the $\mathrm{k}_{\mathrm{nr}}$ of [4]-cyclocarbazoles is twice larger than that of [8]CPP $\left(1.3\right.$ vs $\left.0.7 \times 10^{8} \mathrm{~s}^{-1}\right)$. This shows that the rigidification induced by the bridges in [4]-cyclocarbazoles does not decrease the $\mathrm{k}_{\mathrm{nr}}$ values as often observed in linear compounds. This conclusion is confirmed by looking at [4]CdiEt-F, which displays a lifetime of 7.9 ns with $k_{r} / k_{n r}$ values of 3.0/9.6 $\times 10^{7} \mathrm{~s}^{-1}$. $\mathrm{k}_{\mathrm{r}}$ is identical to that measured for [4]cyclocarbazoles whereas $k_{n r}$ is slightly larger than that of [8]CPP. This confirms that the bridges do not attenuate non radiative pathways by rigidifying the molecular system. Finally, it should also be mentioned that the photophysical properties of the present [4]-cyclocarbazoles linked by their para positions are drastically different from those of meta linked [4]-cyclocarbazoles recently reported in literature. ${ }^{53}$ Indeed, the meta linkages do not form a nanoring with the resulting radially directed orbitals and the photophysical properties are significantly affected.

Absorption spectra of the three [4]-cyclocarbazoles in thin film (Figure 5 top) are very similar to those in solution except for a small bathochromic shift of $10 \mathrm{~nm}$ (337 nm in solution vs $347 \mathrm{~nm}$ in thin solid film, Table 2), indicating the absence of strong aggregation in the solid state. [8]CPP also display a small bathochromic shift between solution and solid of $13 \mathrm{~nm}$ whereas the absorption spectra of [4]C-diEt-F in solution and in thin film are superimposed with a maximum at $347 \mathrm{~nm}$. [4]C-diEt-F also exhibits the shortest increase of FWHM from solution to thin film (resp. 35 and $43 \mathrm{~nm}$ for [4]C-diEtF, 39 and $100 \mathrm{~nm}$ for [4]C-Et-Cbz and 45 and $100 \mathrm{~nm}$ for [8]CPP). This points to a different molecular packing in the solid state (as exposed above) and more isolated chromophores in the case of [4]C-diEt-F, as will be detailed below.

Emission spectroscopy (Figure 5 bottom left) is more sensitive to environment effects, which may significantly impact the energy of excited states. ${ }^{54-56}$ [4]C-Et-Cbz presents an emission in thin film with a maximum at $525 \mathrm{~nm}$ and a shoulder at $498 \mathrm{~nm}$, significantly red-shifted by $38 \mathrm{~nm}$ compared to its solution spectrum ( $\lambda$ max $=487 \mathrm{~nm})$. [8]CPP presents the same behavior with a similar shift of $42 \mathrm{~nm}$ between solution and thin film. The red shift observed in the case of [4]C-diEt-F is smaller (15 nm), reflecting different supramolecular arrangements in the solid state between the nanorings. 
Table 2. Photophysical data of [8]CPP, [4]C-diEt-F and [4]-cyclocarbazoles in solution and in thin film.

\begin{tabular}{|c|c|c|c|c|c|}
\hline & [8]CPP & [4]C-diEt-F & [4]C-Et-Cbz & [4]C-Bu-Cbz & [4]C-Hex-Cbz \\
\hline & \multicolumn{5}{|c|}{ In solution (cyclohexane) } \\
\hline 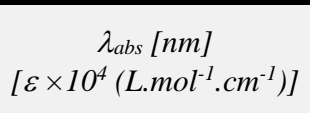 & 333 (1.9) & 347 (9.1) & $\begin{array}{l}337(8.3) \\
292(5.7) \\
256(8.5)\end{array}$ & $\begin{array}{l}337(7.7) \\
293(5.3) \\
257(7.9)\end{array}$ & $\begin{array}{c}337(10.3) \\
293(7.2) \\
257(10.7)\end{array}$ \\
\hline $\begin{array}{c}\lambda_{\text {em,max }}[\mathrm{nm}] \\
\left(\lambda_{\text {exc }}=340 \mathrm{~nm}\right)\end{array}$ & 528 & 487 & 487 & 483 & 482 \\
\hline Quantum yield & 0.25 & 0.24 & 0.19 & 0.20 & 0.20 \\
\hline$\tau_{f}[n s]$ & 10.6 & 7.9 & 6.2 & 6.2 & 6.3 \\
\hline$k_{r}\left(\times 10^{7}\right)\left[\mathrm{s}^{-1}\right]$ & 2.4 & 3.0 & 3.1 & 3.1 & 3.2 \\
\hline \multirow{2}{*}{$k_{n r}\left(\times 10^{8}\right)\left[\mathrm{s}^{-1}\right]$} & 0.70 & 0.96 & 1.3 & 1.3 & 1.3 \\
\hline & \multicolumn{5}{|c|}{ In thin film } \\
\hline$\lambda_{a b s}[\mathrm{~nm}]$ & $346^{\mathrm{a}}$ & $347^{b}$ & $\begin{array}{l}347^{a} \\
295 \\
267\end{array}$ & $\begin{array}{l}347^{a} \\
295 \\
267\end{array}$ & $\begin{array}{l}347^{a} \\
295\end{array}$ \\
\hline $\begin{array}{c}\lambda_{e m, \max }[\mathrm{nm}] \\
\left(\lambda_{\text {exc }}\right)\end{array}$ & $\begin{array}{c}570 \\
(400)^{\mathrm{a}}\end{array}$ & $\begin{array}{c}502 \\
(340)^{\mathrm{b}}\end{array}$ & $\begin{array}{l}498 ; 525 \\
(350)^{\mathrm{a}}\end{array}$ & $\begin{array}{l}495 ; 518 \\
(350)^{\mathrm{a}}\end{array}$ & $\begin{array}{l}491 ; 514 \\
(350)^{\mathrm{a}}\end{array}$ \\
\hline Quantum yield & $0.08^{\mathrm{b}}$ & $0.12^{\mathrm{b}}$ & $0.15^{b}$ & $0.13^{\mathrm{b}}$ & $0.18^{\mathrm{b}}$ \\
\hline
\end{tabular}

a. From thermally evaporated thin film, b. from spin-coated film.

Analysis of the short intermolecular distances occurring in the crystals can shed light on this behavior (Figure 5 right). In the case of [4]C-Et-Cbz, the nanorings form a tube-like structure along the b-axis and are stacked along the a-axis with a particularly short C-C distance of $3.31 \AA$ between two neighbouring carbazoles. This distance is shorter than the sum of the van der Waals radii $\left(\mathrm{dC}-\mathrm{C}=3.4 \AA^{57}\right.$ ). Several other short C-C distances between the carbazole units, comprised between 3.44 and $3.49 \AA$ (Figure S16), are also detected as a signature of $\pi-\pi$ interactions in the crystal. As explained above, the analysis of the molecular packing of [4]C-diEt-F also shows a pseudo-tubular supramolecular arrangement but this time along the c-axis. However, oppositely to the above mentioned arrangement of [4]C-Et-Cbz, no short C/C distance is detected between two fluorene units. This difference in term of molecular packing (and the resulting different $\pi-\pi$ interactions) between [4]C-Et-Cbz and [4]CdiEt-F can explain the difference observed between the emission spectra in solution and in thin solid film. Note that the same behavior is also detected in absorption though with a smaller amplitude.

The packing diagram of [8]CPP (Figure 5 right) confirms its influence on the photophysical properties as very short C-C distances of $3.31 \AA$ are also detected between the phenyl units (many short $\mathrm{C}-\mathrm{H}$ distances are also measured, see Figure S17). This behavior, similar to that of [4]C-Et-Cbz (the short distance is observed along the crystallographic axis a for both), matches the trend observed in the emission spectra. The two other [4]-cyclocarbazoles [4]C-Bu-Cbz and [4]C-Hex$\mathbf{C b z}$ demonstrate the influence of the alkyl chains on the solid state emission. Indeed, the intensity of the shoulder observed for [4]C-Et-Cbz at $498 \mathrm{~nm}$ is clearly increased in [4]C-Bu$\mathbf{C b z}$ and [4]C-Hex-Cbz (Figure 5 bottom-middle). The maximum of the emission spectra is therefore shifted from $525 \mathrm{~nm}$ in [4]C-Et-Cbz to $491 \mathrm{~nm}$ in [4]C-Hex-Cbz, pointing to a different molecular arrangement in the thin film. This molecular engineering strategy appears as an interesting tool to tune the solid-state electronic properties of [4]cyclocarbazoles. The charge transport studies presented below confirm the different layout of the nanorings in the solid state.

Finally, the absolute quantum yields in the solid state have been determined. For [8]CPP, the quantum yield is divided by 3 , from 0.25 in solution to 0.08 in solid state. For the fluorene analogue [4]C-diEt-F, the quantum yield is divided by $2(0.24 \rightarrow 0.12)$, showing the interest of the bridge incorporation in the fluorophore efficiency in the solid state. Remarkably, for [4]-cyclocarbazoles, there is only a slight decrease of the quantum yield from $0.19-0.20$ in solution to 0.13-0.18 in thin film. Thus, in this family of nanorings, the quantum yield is almost maintained between solution and thin film. This is an interesting finding for the future design of cyclocarbazole nanorings for solid state optoelectronics and is a very different behavior compared to linear fluorophores such as oligofluorenes, whose quantum yield dramatically drops down due to the stacking of the fluorenes. ${ }^{23}$

\subsection{Charge Transport Studies.}

OFET electrical characterizations and I-V measurements in two-terminal devices have been finally performed to evaluate the charge transport properties of [4]-cyclocarbazoles and model [8]CPP either in-plane or out-of-plane, respectively (Table 3, Figure 6). Note that only one example of a SCLC device incorporating a nanoring ${ }^{35}$ has been reported but no CPP have been incorporated in OFET to date; only theoretical descriptions of the charge transport have been reported. ${ }^{26,29,58}$

First, the nanorings have been incorporated as active layer in OFETs possessing a bottom-gate bottom-contact (BG-BC) architecture (the device structure is presented in Figure S25 ${ }^{59}$ ). This BG-BC structure, in which the active layer is evaporated in the last step, prevents any structural effect resulting from the deposition of other layers. ${ }^{60-61}$ The temperature dependence and the gate-source voltage $\mathrm{V}_{\mathrm{GS}}$ dependence were analysed to estimate the field effect (FE) hole mobility $\mu_{\mathrm{FE}}$ and assess the influence of the alkyl chains borne by the nitrogen atoms. It is worth stressing that the four nanorings can be easily evaporated $\left(2.10^{-7}\right.$ mbar with temperature between 190 and $230^{\circ} \mathrm{C}$ ). 

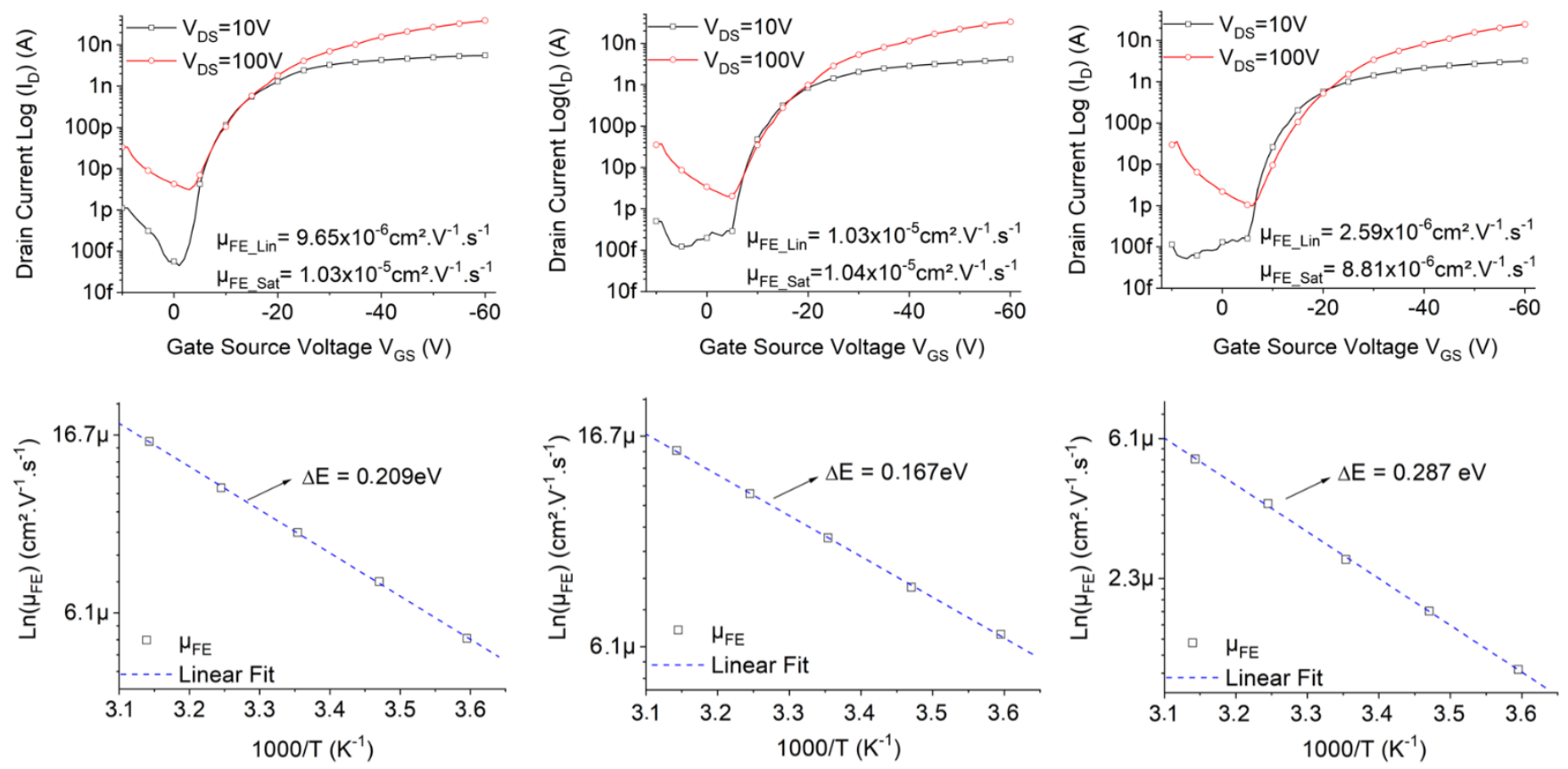

Figure 6. Transfer characteristics in linear and saturated regimes (Top) and Arrhenius plot of FE mobility $\ln \left(\mu_{\mathrm{FE}}\right)$ as a function of 1000/T (bottom) of [4]C-Et-Cbz (left), [4]C-Bu-Cbz (middle) and [4]C-Hex-Cbz (right).

The first striking result is obtained with [8]CPP. Indeed, no $\mu_{\mathrm{FE}}$ is measured for this molecule. Since the calculations yield significant electronic couplings between molecules in the active layer (see below), this suggests that [8]CPP does not allow efficient injection of charges and hence accumulation of holes at the OSC/insulator interface in the transport channel. This can be tentatively assigned to the deeper HOMO level of this derivative among the nanorings studied (as supported by CV data) and/or a different contact geometry at the interface limiting the electronic overlap between the nanorings and the metallic surface as further discussed below.

In the case of [4]-cyclocarbazoles, the situation is different. We observe a strong impact of the carbazole unit on the charge transport properties. The transfer characteristics of the three molecules are presented in Figure 6. The first observation concerns the FE mobility in the saturated regime $\mu_{\mathrm{FE} \_ \text {sat }}\left(\mathrm{V}_{\mathrm{DS}}\right.$ $=100 \mathrm{~V})$. The extracted values are very close for the 3 molecules: $1.03 \times 10^{-5}, 1.04 \times 10^{-5}$ and $8.81 \times 10^{-6} \mathrm{~cm}^{2} . \mathrm{V}^{-1} \cdot \mathrm{s}^{-1}$ for [4]C-Et-Cbz, [4]C-Bu-Cbz and [4]C-Hex-Cbz, respectively. The values $\mu_{\mathrm{FE} \_ \text {sat }}$ are obtained at high electric field $\mathrm{V}_{\mathrm{DS}}$. In this condition, traps into the OSC are filled and do not impact the carrier mobility. To compare the effect of the ethyl, butyl and hexyl chains, it is more interesting to focus on the capability of the OSC to accumulate charges at the OSC/insulator interface and on the FE mobility in linear regime. Indeed, in the case of disordered semiconducting layer, the linear FE mobility is dependent on the gate-source voltage $\mathrm{V}_{\mathrm{Gs}}$.

The ability to accumulate charges at the OSC/insulator interface is reflected through two key electrical parameters: the threshold voltage $\left(\mathrm{V}_{\mathrm{TH}}\right)$ and subthreshold slope (SS). $\mathrm{V}_{\mathrm{TH}}$ is the gate-source voltage needed for the channel to be populated while SS corresponds to the voltage required to increase the current at the OSC/insulator interface by one order of magnitude. This last parameter is very dependent on the defect density at the insulator/OSC interface and into the OSC itself. Indeed, if the density of traps is high, most of the carriers initially injected do not participate in the electrical conduction within the channel. SS is thus intimately related to the actual organization of the molecules within the active layer as it is also the case for the FE mobility in the linear regime. The lowest SS is measured for [4]C-Bu-Cbz with $\mathrm{SS}=0.89 \mathrm{~V} / \mathrm{dec}$ while the highest SS is observed for [4]CHex-Cbz, $1.61 \mathrm{~V} /$ dec. An intermediate value is obtained for [4]C-Et-Cbz with SS $=1.29 \mathrm{~V} / \mathrm{dec}$. The extraction of $\mathrm{V}_{\mathrm{TH}}$ also confirms this trend, the lowest $\mathrm{V}_{\mathrm{TH}}$ being detected for the butyl chain $\left(\mathrm{V}_{\mathrm{TH}}=-12.8 \mathrm{~V}\right)$ and the highest $\mathrm{V}_{\mathrm{TH}}$ for the hexyl chain $\left(\mathrm{V}_{\mathrm{TH}}=-13.9 \mathrm{~V}\right)$. These data suggest that the butyl chain promotes a good organization of the molecules in thin films whereas the hexyl chain increases the density of structural defects, and hence of traps for the charge carriers. Since the molecular packing has indeed a high impact on the OSC/insulator interface, AFM studies have been performed (Figure 7). The film surface of both [4]C-Bu-Cbz (root mean roughness $\left.\mathrm{R}_{\mathrm{q}}=0.421 \mathrm{~nm}\right)$ and [4]C-Et-Cbz $\left(\mathrm{R}_{\mathrm{q}}=0.837 \mathrm{~nm}\right)$ remarkably presents a regular and smooth morphology with low surface roughness. Oppositely, [4]C-Hex-Cbz $\left(\mathrm{R}_{\mathrm{q}}=1.47 \mathrm{~nm}\right)$ and more significantly [8]CPP $\left(\mathrm{R}_{\mathrm{q}}=3.67 \mathrm{~nm}\right)$ display a high surface roughness (see Table S8). These results are in full accordance with the SS and $\mathrm{V}_{\mathrm{TH}}$ values presented above and reflect the different molecular arrangements of the four nanorings. These data are also consistent with the differences observed between linear and saturated FE mobilities. Indeed, in the case of the $[4] \mathbf{C}-\mathbf{B u}-\mathbf{C b z}$, the linear FE mobility $\left(\mu_{\mathrm{FE} \_ \text {lin }}=1.03 \times 10^{-5} \mathrm{~cm}^{2} . \mathrm{V}^{-1} \cdot \mathrm{s}^{-1}\right)$ is almost identical to the saturated FE mobility $\left(\mu_{\mathrm{FE} \_ \text {sat }}=1.04 \times 10^{-5} \mathrm{~cm}^{2} . \mathrm{V}^{-1} \cdot \mathrm{s}^{-1}\right)$, which indicates that the linear FE mobility is almost unaffected by traps into the OSC. In contrast, the highest difference between linear and saturated FE mobility is measured for [4]C-HexCbz with $\mu_{\mathrm{FE} \_ \text {lin }}=2.59 \times 10^{-6} \mathrm{~cm}^{2} . \mathrm{V}^{-1} . \mathrm{s}^{-1}$ and $\mu_{\mathrm{FE} \_ \text {Sat }}=8.81 \times 10^{-6}$ $\mathrm{cm}^{2} . \mathrm{V}^{-1} . \mathrm{s}^{-1}$. In addition, [4]C-Hex-Cbz displays the lowest linear FE mobility in the series. Interestingly, calculations performed on single crystal structures demonstrate that [4]CHex-Cbz exhibits the weakest electronic couplings between molecules (see below), thus making it, for all these reasons, the worse performing nanoring. To sum up, the electrical

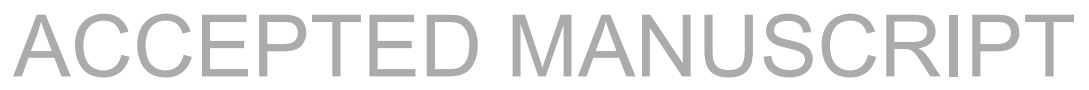


characteristics and morphological data are in complete accordance and shows the importance of the bridge and of the alkyl chains in the OFET performance.

Measurements of linear FE mobilities as a function of temperature were carried out to further confirm this trend. For disordered materials, a hopping model is typically inferred to describe charge transport. The static disorder in this type of materials supplemented by the dynamic disorder induced by thermal agitation leads to a pronounced localization of the charges over a single molecule.The accessible states for transport are then distributed in energy and spatially and the conduction occurs via carrier jumps between such localized states. The probability of jumping from a site to another is typically described nowadays by Marcus theory. ${ }^{62}$ The activation barrier for a hopping process is there given by $(\Delta \mathrm{E}+\lambda)^{2} / 4 \lambda$, with $\Delta \mathrm{E}=\mathrm{E}_{\mathrm{f}}-\mathrm{E}_{\mathrm{i}}$ the difference between the initial and final site energies and $\lambda$ the reorganization energy typically dominated by the geometric changes in the molecule when going from the neutral to the charged state and vice versa. ${ }^{34}$ Temperature-dependent measurements thus allow the evaluation of the average activation energy $\Delta \mathrm{E}$ for charge hopping.

In the case of the present [4]-cyclocarbazoles, the logarithm plot of FE mobility $\ln \left(\mu_{\mathrm{FE}}\right)$ evolves linearly with the inverse of the temperature $(1000 / T)$. Extraction of the activation barrier from these curves confirms the observations made from the transfer characteristics. Indeed, the butyl chain appears to favor the molecular organization in the film since the trapping energy is the lowest with $\Delta \mathrm{E}=0.167 \mathrm{eV}$. In contrast, the hexyl chain yields the largest activation energy with $\Delta \mathrm{E}=0.287 \mathrm{eV}$ while [4]C-Et-Cbz provides an intermediate value of $\Delta \mathrm{E}=0.209 \mathrm{eV}, \mathrm{eV}$ in accordance with roughnesses extracted from AFM measurements (Figure 7, Table S8).

Table 3. Main electrical characteristics of devices made with [4]-cyclocarbazoles and [8]CPP.

\begin{tabular}{|c|c|c|c|c|}
\hline & [8]CPP & $\begin{array}{l}\text { [4]C- } \\
\text { Et-Cbz }\end{array}$ & $\begin{array}{c}\text { [4]C- } \\
\text { Bu-Cbz }\end{array}$ & $\begin{array}{c}{[4] \mathrm{C}-} \\
\text { Hex-Cbz }\end{array}$ \\
\hline $\begin{array}{l}\mu_{\text {FElin }} \times 10^{-5} \\
\left(\mathrm{~cm}^{2} \cdot V^{-1} \cdot \mathrm{s}^{-1}\right)\end{array}$ & $a$ & 0.965 & 1.03 & 0.259 \\
\hline $\begin{array}{l}\mu_{\text {FEsat }} \times 10^{-5} \\
\left(\mathrm{~cm}^{2} \cdot V^{-1} \cdot \mathrm{s}^{-1}\right)\end{array}$ & $a$ & 1.03 & 1.04 & 0.881 \\
\hline$V_{T H}(V)$ & $a$ & -13.1 & -12.8 & -13.9 \\
\hline SS (V/Dec) & $a$ & 1.29 & 0.89 & 1.61 \\
\hline $\begin{array}{c}\mu_{\text {carrier }} \times 10^{-4} \\
\left(\mathrm{~cm}^{2} \cdot V^{-1} \cdot \mathrm{s}^{-1}\right)\end{array}$ & 0.00121 & 2.71 & 2.78 & 1.37 \\
\hline$\Delta E(e V)$ & $b$ & 0.209 & 0.167 & 0.287 \\
\hline
\end{tabular}

a. Not measurable; b. Not determined

The electrical performance of a transistor is known to be very dependent on the device architecture. In this study, the specific organization of the molecules in the thin film could be induced by the nature of the interface between the OSC and the insulator. The insulator is here an epoxy resin type SU8 2000.5, which has already been used in OFETs ${ }^{59-61}$ exhibiting very high FE mobilities $\left(\sim 1.5 \mathrm{~cm}^{2} . \mathrm{V}^{-1} \cdot \mathrm{s}^{-1}\right)$. However, the interfacial interactions could be favorable for some OSCs but not for others. To confirm that the structural organization of the molecules in thin films is not strongly driven by the nature of the insulator, the carrier mobilities were also extracted in a two-terminal device by applying the Mott-Gurney model to the I-V measurements (space-charge-limited current SCLC transport, see details in SI). Another advantage of this approach is to probe charge transport in the out-of-plane direction in contrast to the FE measurements. To promote the injection of holes into the OSC, a "sandwich" structure was fabricated with two gold electrodes (work function: $-5.3 \mathrm{eV}$ ). The resulting I-V characteristics are shown in Figure S26.

The measurement of the SCLC carrier mobility fully confirms what has been discussed above from the transfer characteristics and from the temperature measurements. [4]CBu-Cbz shows better transport properties with carrier mobility $\mu_{\text {carrier }}=2.78 \times 10^{-4} \mathrm{~cm}^{2} \cdot \mathrm{V}^{-1} \cdot \mathrm{s}^{-1}$. In agreement with the FE data in the saturated regime, [4]C-Et-Cbz behaves similarly with $\mu_{\text {carrier }}=2.71 \times 10^{-4} \mathrm{~cm}^{2} \cdot \mathrm{V}^{-1} \cdot \mathrm{s}^{-1}$. [4]C-Hex-Cbz is also close in terms of electrical performance with a mobility $\mu_{\text {carrier }}=1.37 \times 10^{-4} \mathrm{~cm}^{2} . \mathrm{V}^{-1} \cdot \mathrm{s}^{-1}$. Note that for this last molecule, we observe that the electric field to be applied to fill the defects is higher, in deep consistency with the larger activation energy inferred from the temperature measurements. Finally, the mobility of [8]CPP has been measured following the same experimental protocol. Doing so, a very low mobility value of $1.21 \times 10^{-7} \mathrm{~cm}^{2} \cdot \mathrm{V}^{-1} \cdot \mathrm{s}^{-1}$ is obtained. This mobility is ca 3 orders of magnitude lower than that of [4]-cyclocarbazoles in agreement with the significant differences detected by AFM studies (Figure 7). This shows how a subtle structural modification of the nanoring backbone can have important consequences on the charge transport.

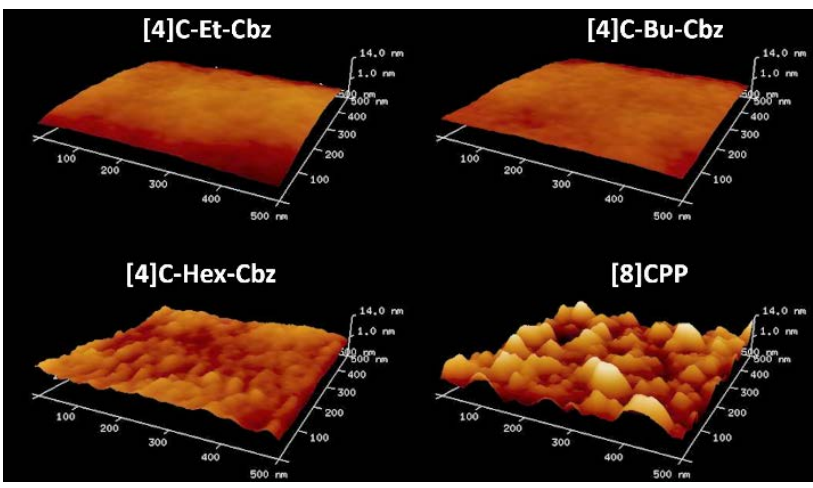

Figure 7. 2D $\left(500 \times 500 \mathrm{~nm}^{2}\right)$ AFM images of semiconducting layer deposited under vacuum on SU8 insulating layer

Finally, the stability of the devices, which is a central feature for practical use, has been evaluated. First, it is worth mentioning that after 18 months of storage under a nitrogen atmosphere, the OFET characteristics of both [4]C-Et-Cbz and [4]C-Bu-Cbz remain the same (see Figure S28), whereas those of [4]C-Hex-Cbz are damaged. This can be again linked to the higher defect density found in the latter and highlights that the alkyl chain is also involved in the stability of the devices. The electrical stability of an OFET can be then evaluated by gate bias stress analysis. In such conditions, it is known that $\mathrm{V}_{\mathrm{TH}}$ shifts and the drain current $\mathrm{I}_{\mathrm{D}}$ decreases. ${ }^{61} \mathrm{~A}$ stretched exponential fit has been applied to $V_{\mathrm{TH}}$ shift with stress time. The good agreement between experimental and 
simulated data highlights a reorganization of the OSC layer with the electrical stress. Because the density of structural defects of [4]C-Hex-Cbz is higher than that of [4]C-Et-Cbz and [4]C-Bu-Cbz, electrical stress significantly decreases its electrical performance (Figure S27). From this stretched exponential fit, characteristic trapping time of carriers has also been evaluated. [4]C-Hex-Cbz exhibits a very short trapping time $t=558.9 \mathrm{~s}$ leading to a strong increase of $\mathrm{V}_{\mathrm{TH}}$. For [4]CEt-Cbz and [4]C-Bu-Cbz, this characteristic trapping time is higher with $\mathrm{t}=4623.4 \mathrm{~s}$ and $\mathrm{t}=39045.2 \mathrm{~s}$ respectively. These results can also be linked to the roughness of the film, with the lowest value obtained for [4]C-Bu-Cbz and the highest value for [4]C-Hex-Cbz (see above).

In order to better understand the possible origins for the very low mobility in [8]CPP and to assess the intrinsic transport properties of the nanorings, we have computed the electronic coupling between the HOMO levels of adjacent molecules in the single crystal structures. This parameter, often referred to as transfer integral, is indeed a central quantity governing the mobility values whatever the transport model considered (band or hopping regime). This key parameter reflects the degree of electronic overlap between the wave functions of adjacent molecules and has to be maximized. It is highly sensitive to the relative orientation of the molecules and allows theoreticians to draw maps of the most probable pathways a charge would take in bulk structure, thus assessing the dimensionality of charge transport. Moreover, the weak van der Waals interactions between molecules cause intermolecular vibrational modes to induce large molecular displacements, greatly affecting in turn electronic couplings in many occasions. We must thus include another important factor when analyzing charge transport through modeling methods and that is by how much the electronic coupling is spread by phonons at ambient temperature. In other words, we must consider as well the standard deviation of the distribution of electronic couplings induced by thermal motion. Comparing electronic couplings at both the static and dynamic levels is thus important to compare the nanorings performance.

To evaluate performances of the materials at the static level, we computed all the transfer integrals involving the molecules in the central unit cell of a $3 \times 3 \times 3$ super cell. The results are exposed in Figure 8 . The total number of pairs of neighbors stems from the amount of inequivalent molecules there are in one unit cell. This explains why the total number of couplings is different for each system. The maximum electronic couplings in the carbazole nanorings are slightly lower than the values observed in the CPP systems where the average transfer integral is on the order of $10 \mathrm{meV} .^{26,29}$ From this plot, one realizes that, intrinsically, the new generation of bridged [4]-cyclocarbazoles does not exceed the range of transfer integrals of the unbridged nanoring [8]CPP. Herein, [8]CPP displays the highest HOMO coupling, ca $18.3 \mathrm{meV}$ along a molecular axis. These molecular pathways are highlighted by green arrows in Figure 9. A larger set of couplings also appears around $10 \mathrm{meV}$ along two non-parallel molecular pathways that cross each other in the $(b c)$ plane of the system.

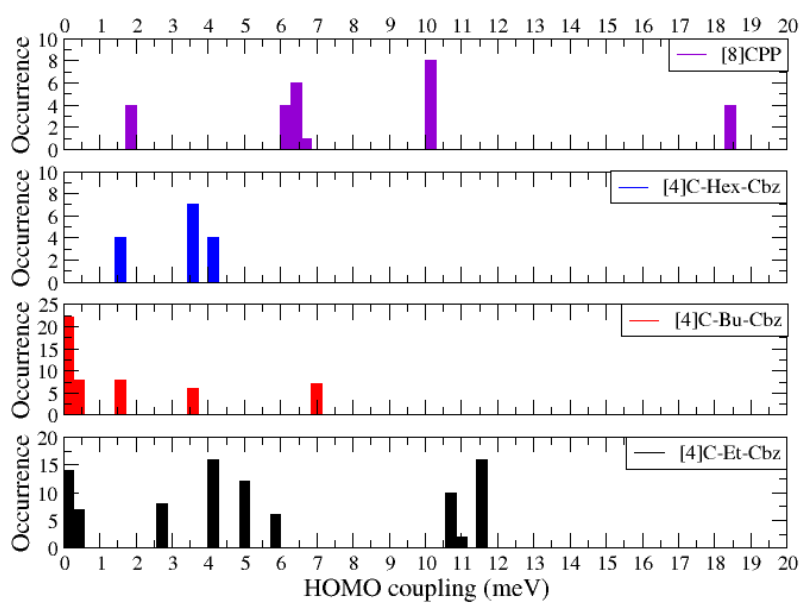

Figure 8. Energetic distribution of transfer integral values for the three carbazole nanorings vs [8]CPP in a $3 \times 3 \times 3$ supercell. The number of different electronic coupling is didacted by the crystal packing and the number of molecules in the unit cell.

This molecular plane appears in yellow in Figure 9 and the orientation of the two pathways are highlighted by orange arrows. Electronic couplings in this region of the distribution are so close that our bin size was too large to separate them. The $18 \mathrm{meV}$ molecular axis goes through this plane, making [8]CPP the closest material to be of $3 \mathrm{D}$ transport nature in the scope of this study, despite relatively low couplings compared to the best organic OSCs with high transfer integrals typically between 50 and $100 \mathrm{meV}^{63-64}$

We have next computed the way lattice vibrational modes activated by temperature modulates the electronic couplings via molecular dynamics (MD) simulations. Once transfer integrals were computed from snapshots extracted from the MD run, we obtained the HOMO coupling distributions. For [8]CPP, the average coupling associated to the green direction is 11.6 vs $18.3 \mathrm{meV}$ in the crystalline structure. The average coupling associated to the dimers in the yellow plane is around 3.71 vs $10.1 \mathrm{meV}$ in the experimental structure. The thermal vibrations of the lattice lead to moderate fluctuations in the transfer integrals, with standard deviation of $5.27 \mathrm{meV}$ for the green coupling and $2.81 \mathrm{meV}$ for the yellow couplings; all relevant information about electronic couplings and standard deviations can be found in Table S22. Electronic coupling distributions relevant to this description are presented in figure S33-35. At this stage, we can thus conclude that the absence of current in devices incorporating [8]CPP does not originate from an intrinsic property of the bulk of the material. Although weak electronic couplings prevail between the nanorings, [8]CPP exhibits a rather unique $3 \mathrm{D}$ character in contrast to the most performant OSCs $^{65}$ typically organized in layers with a dominant 2D character. ${ }^{66}$ The experimental data seems to point towards injection problems.

CV data and DFT calculations highlight a difference in HOMO levels on the order of $0.1 \mathrm{eV}$ between [8]CPP and the carbazole nanorings. The current going through the interface is proportional to the exponential of the injection barrier, ${ }^{67}$ which is thus larger for [8]CPP.

\section{ACCEPTED MANUSCRIPT}



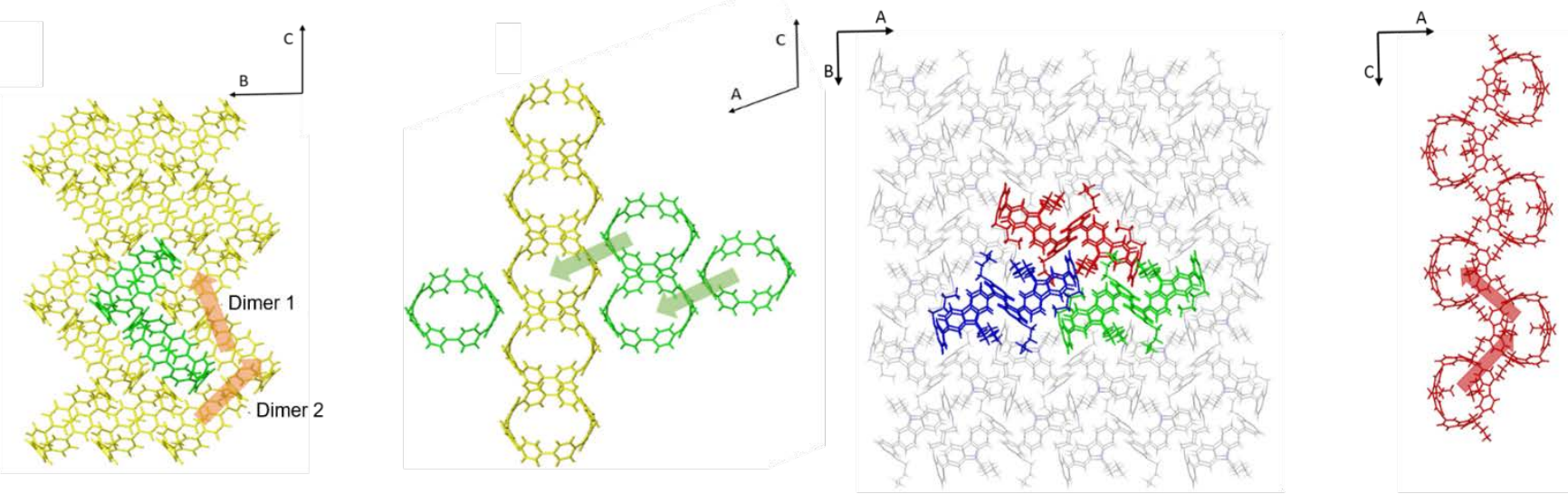

[8]CPP
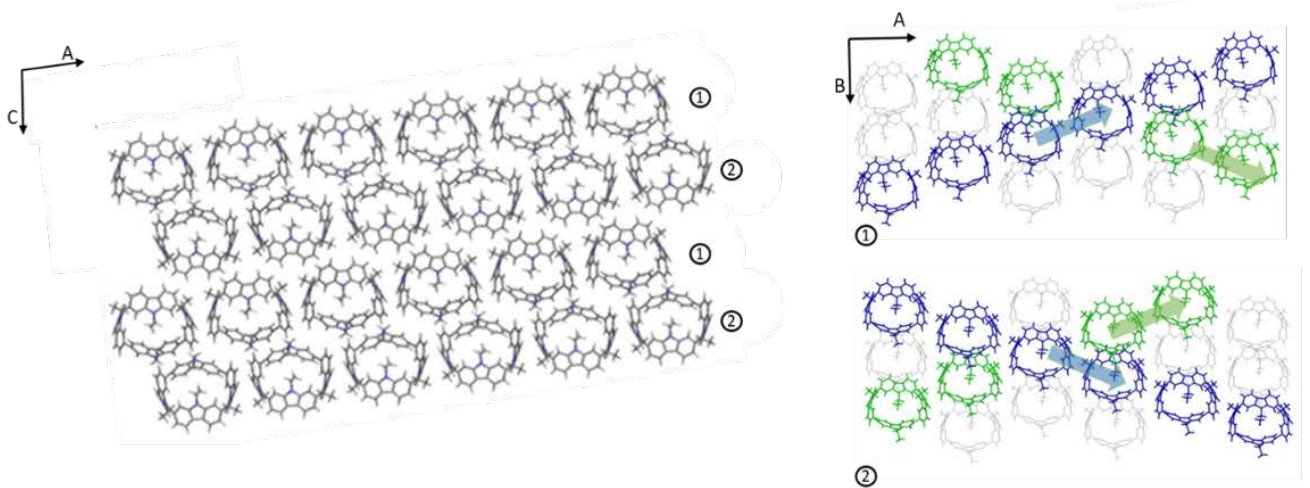

[4]C-Bu-Cbz

[4]C-Et-Cbz

Figure 9. Most efficient hole transport networks in [8]CPP (Green: molecules taking part in the 18 meV coupling. Yellow : plane defined by the two $10 \mathrm{meV}$ molecular pathways), in [4]C-Bu-Cbz ( $b c)$ molecular planes hold the most probable hole pathways for this system) and in [4]C-Et-Cbz $(3 \times 3 \times 1$ supercell seen from the $(a c)$ plane; the 1 and 2 labels on the scheme correspond to the respective conducting planes in the $(a b)$ plane).

Couple this to the idea that if the metal-molecule interaction is strong enough to distort [8]CPP at the interface or if the metal is not in direct contact with the aromatic rings, this might impede efficient charge injection in the devices. Note that carbazole-based nanorings are much less likely to be distorted at the metallic interfaces since they are more rigid, and that injection barrier is very material dependent, even when considering the same electrode. ${ }^{68}$ The electrode/OSC contact geometry is actually surely modified by the size of the pending alkyl chains. Future works in the field on charge carriers in nanorings will provide relevant data on this feature.

From the electronic couplings point of view, the materials displaying the less efficient charge transport is [4]C-Hex-Cbz with an average maximum at $4 \mathrm{meV}$. Such couplings are associated to directions in the $(b c)$ plane, revealing a weak 2D transport. [4]C-Bu-Cbz does not pack very well in favor of charge transport, as the highest HOMO coupling reaches 7 $\mathrm{meV}$ along a single direction. In the scope of a hopping model (see SI for details), [4]C-Bu-Cbz requires the holes to jump in a zigzag fashion along the $c$ axis as shown in Figure 9 (red arrows). Three of these recognizable columns (red, green and blue in Figure 9) go through the unit cell. All possible transfer integrals between these columns are close to $0 \mathrm{meV}$, indicating there are hardly any chances for a hole to jump on a neighboring $7 \mathrm{meV}$ molecular pathway. Fluctuations of the electronic couplings in these zigzag columns reaches $1.2 \mathrm{meV}$ and are illustrated in SI.
[4]C-Et-Cbz is the most promising compound among the systems under theoretical investigation. It has 8 molecules per unit cell, where each pair along the blue and green molecular axes in the bc plane forms a cluster of large HOMO couplings, between 10 and $12 \mathrm{meV}$, Figure 8 . The hole transport network in [4]C-Et-Cbz crystals thus only extends in 2D. Thermal fluctuations of two selected dimers lead once again to standard deviations on the order of 4-5 meV. Transfer integral distributions can be found in SI, Figure S35.

Although standard mean deviations of the electronic couplings in carbazole nanorings represent $50-100 \%$ of their average value, they are rather low (1-5 meV, see table S21) compared to state of the art materials such as OSC based on pentacene $\left(40-50 \mathrm{meV}^{69}\right)$, anthracene $\left(20-35 \mathrm{meV},{ }^{70}\right)$ or rubrene $\left(20-50 \mathrm{meV}^{64}\right)$. Rod-like molecules such as pentacene, naphtho[2,3-b]naphtho[2',3':4,5]thieno[2,3d]thiophene (DNTT) and benzothieno[3,2b][1]benzothiophene (BTBT) derivatives typically display high charge-phonon couplings that are detrimental to transport, the most notable being a shearing mode of vibration along the longest axis of the molecules. ${ }^{71}$ This normal mode is tightly correlated to the flat and elongated shape of the molecule. Nanorings, because of their geometrical features, might be an interesting solution for crystal engineering to avoid this problem. Interestingly, this study suggests that designing any molecular structure beyond simple rod-like shapes but with high electronic couplings could help reducing

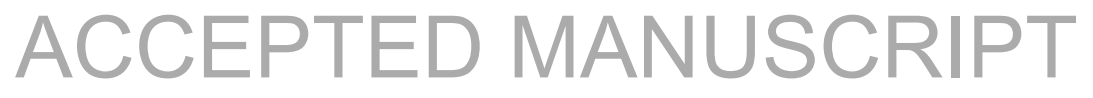


the often detrimental impact of lattice vibrations on charge transport.

\section{Conclusion}

This work reports the first detailed structure-properties-device performance relationship study of functional materials based on nanoring systems i.e. [4] cyclo- $N$-alkyl-2,7-carbazoles. The nanorings have been synthesized through an optimized synthetic protocol leading to a very high yield of ca $60 \%$. As far as we are aware, this yield is among the highest reported to date for this approach. Electrochemical, photophysical and structural properties have been then unraveled to elucidate the key role played by the bridge and by its substitution. It appears that [4]-cyclocarbazoles present many promising characteristics such as the stability of the quantum yield in the solid state. As the supramolecular arrangement can be tuned by the chain borne by the nitrogen atom, the consequences on the solid state properties of the nanorings are important. The charge transport properties are impacted and the OFET characteristics of the three [4]-cyclocarbazoles appear to be different and modulated by the size of the alkyl chain. FE mobility values of ca $10^{-5} \mathrm{~cm}^{2} . \mathrm{V}^{-1} \cdot \mathrm{s}^{-1}$ were recorded for the [4]cyclocarbazoles, whereas non-bridged benchmark [8]CPP does not display any FE mobility. Similarly, the SCLC mobility of [4]-cyclocarbazoles appears to be three order of magnitudes higher than that of [8]CPP highlighting the strong effect of the bridging on the charge transport properties. At the theoretical level, the computed electronic couplings between HOMOs of adjacent molecules nevertheless indicate that [8]CPP is intrinsically a better hole transporter than the [4]-cyclocarbazoles, provided that charges can be injected efficiently. Analysis of the fluctuations in the electronic couplings induced by thermal agitation points to a small dynamic disorder, most often detrimental, compared to the rod-like best performing organic semiconductors. It is noteworthy mentioning that [4]C-Et-Cbz and [4]C-Bu-Cbz based devices remain stable at the year time scale and under electric stress showing the potential of this family of nanorings.

This study opens the way to the development of nanorings in electronics. With further molecular designs to tune the HOMO/LUMO energy levels and/or the intermolecular interactions, the mobility values will be surely rapidly increased. The rational construction of nanorings for application in organic devices is now the next stage of development and we are putting efforts along this direction.

\section{SUPPORTING INFORMATION}

Synthetic procedures, 2D NOESY NMR Spectra, Structural, thermal electrochemical and photophysical properties, charge transport measurements, molecular modelling

\section{ACKNOWLEDGMENT}

This project has received funding from the European Union's Horizon 2020 research and innovation program under grant agreement No 699648 (FRODO Project). This work is supported by the European Union through the European Regional Development Fund (ERDF), the Ministry of Higher Education and Research, the Région Bretagne, the Departement d'Ille et Vilaine and Rennes Metropole, through the CPER Project 2015-
2020 MATECOM-ORGAFLEX. This work was granted access to the HPC resources of CINES under the allocation 2020A0080805032 made by GENCI. The authors would like to thank the ANR ( $\left.{ }^{\circ} 19-C E 05-0024\right)$ and the Region Bretagne (DIADEM) for PhD grant (FL), the CDFIX and CRMPO (Rennes). The work in Mons has been supported by the Marie Curie ITN projects UHMob (GA- 811284) and the Consortium des Équipements de Calcul Intensif (CÉCI), funded by the Fonds de la Recherche Scientifique de Belgique (F.R.S.-FNRS) under grant \# 2.5020.11.

\section{REFERENCES}

(1) Jasti, R.; Bhattacharjee, J.; Neaton, J. B.; Bertozzi, C. R., Synthesis, Characterization, and Theory of [9]-, [12]-, and [18]Cycloparaphenylene: Carbon Nanohoop Structures. J. Am. Chem. Soc. 2008, 130 (52), 17646-17647.

(2) Omachi, H.; Segawa, Y.; Itami, K., Synthesis of Cycloparaphenylenes and Related Carbon Nanorings: A Step toward the Controlled Synthesis of Carbon Nanotubes. Acc. Chem. Res. 2012, 45 (8), 1378-1389.

(3) Darzi, E. R.; Jasti, R., The dynamic, size-dependent properties of [5]-[12]cycloparaphenylenes. Chem. Soc. Rev. 2015, 44 (18), 64016410 .

(4) Golder, M. R.; Jasti, R., Syntheses of the smallest carbon nanohoops and the emergence of unique physical phenomena. Acc. Chem. Res. 2015, 48 (3), 557-66.

(5) Lewis, S. E., Cycloparaphenylenes and related nanohoops. Chem. Soc. Rev. 2015, 44 (8), 2221-2304.

(6) Yamago, S.; Kayahara, E.; Iwamoto, T., OrganoplatinumMediated Synthesis of Cyclic $\pi$-Conjugated Molecules: Towards a New Era of Three-Dimensional Aromatic Compounds. Chem. Rec. 2014, 14 (1), 84-100.

(7) Segawa, Y.; Fukazawa, A.; Matsuura, S.; Omachi, H.; Yamaguchi, S.; Irle, S.; Itami, K., Combined experimental and theoretical studies on the photophysical properties of cycloparaphenylenes. Org. Biomol. Chem. 2012, 10 (30), 5979-5984.

(8) Matsuno, T.; Sato, S.; Iizuka, R.; Isobe, H., Molecular recognition in curved [p]-systems: effects of [p]-lengthening of tubular molecules on thermodynamics and structures. Chem. Sci. 2015, 6 (2), 909-916.

(9) Hitosugi, S.; Nakanishi, W.; Yamasaki, T.; Isobe, H., Bottomup synthesis of finite models of helical (n,m)-single-wall carbon nanotubes. Nat. Commun. 2011, 2, 492.

(10) Hermann, M.; Wassy, D.; Kohn, J.; Seitz, P.; Betschart, M. U.; Grimme, S.; Esser, B., Chiral Dibenzopentalene-based Conjugated Nanohoops through Stereoselective Synthesis. Angew. Chem. Int. Ed. 2021, doi.org/10.1002/anie.202007024.

(11) Wang, J.; Zhuang, G.; Chen, M.; Lu, D.; Li, Z.; Huang, Q.; Jia, H.; Cui, S.; Shao, X.; Yang, S.; Du, P., Selective Synthesis of Conjugated Chiral Macrocycles: Sidewall Segments of $(-) /(+)-(12,4)$ Carbon Nanotubes with Strong Circularly Polarized Luminescence. Angew. Chem. Int. Ed. 2020, 59 (4), 1619-1626.

(12) Hitosugi, S.; Matsumoto, A.; Kaimori, Y.; lizuka, R.; Soai, K.; Isobe, H., Asymmetric Autocatalysis Initiated by Finite Single-Wall Carbon Nanotube Molecules with Helical Chirality. Org. Lett. 2014, 16 (3), 645-647.

(13) Daengngern, R.; Camacho, C.; Kungwan, N.; Irle, S., Theoretical Prediction and Analysis of the UV/Visible Absorption and Emission Spectra of Chiral Carbon Nanorings. J. Phys. Chem. A 2018, 122 (37), 7284-7292.

(14) Sicard, L.; Lucas, F.; Jeannin, O.; Bouit, P. A.; RaultBerthelot, J.; Quinton, C.; Poriel, C., [n]-Cyclo-9,9-dibutyl-2,7-fluorene $(n=4,5)$ : Nanoring Size Influence in Carbon-Bridged Cyclo-paraphenylenes. Angew Chem Int Ed Engl 2020, 59 (27), 11066-11072.

(15) Leonhardt, E. J.; Jasti, R., Emerging applications of carbon nanohoops. Nat. Rev. Chem. 2019, 3 (12), 672-686.

(16) White, B. M.; Zhao, Y.; Kawashima, T. E.; Branchaud, B. P.; Pluth, M. D.; Jasti, R., Expanding the Chemical Space of Biocompatible Fluorophores: Nanohoops in Cells. ACS Cent. Sci 2018, 4 (9), 1173-1178. (17) Miki, K.; Saiki, K.; Umeyama, T.; Baek, J.; Noda, T.; Imahori, H.; Sato, Y.; Suenaga, K.; Ohe, K., Unique Tube-Ring Interactions: 
Complexation of Single-Walled Carbon Nanotubes with Cycloparaphenyleneacetylenes. Small 2018, 14 (26), 1800720.

(18) Iwamoto, T.; Slanina, Z.; Mizorogi, N.; Guo, J.; Akasaka, T.; Nagase, S.; Takaya, H.; Yasuda, N.; Kato, T.; Yamago, S., Partial Charge Transfer in the Shortest Possible Metallofullerene Peapod, La@C82ᄃ[11]Cycloparaphenylene. Chem. Eur. J. 2014, 20 (44), 1440314409.

(19) Nakanishi, Y.; Omachi, H.; Matsuura, S.; Miyata, Y.; Kitaura, R.; Segawa, Y.; Itami, K.; Shinohara, H., Size-Selective Complexation and Extraction of Endohedral Metallofullerenes with Cycloparaphenylene. Angew. Chem. Int. Ed. 2014, 53 (12), 3102-3106.

(20) Xu, Y.; Kaur, R.; Wang, B.; Minameyer, M. B.; Gsänger, S.; Meyer, B.; Drewello, T.; Guldi, D. M.; von Delius, M., Concave-Convex $\pi-\pi$ Template Approach Enables the Synthesis of [10]Cycloparaphenylene-Fullerene [2]Rotaxanes. J. Am. Chem. Soc. 2018, 140 (41), 13413-13420.

(21) Sakamoto, H.; Fujimori, T.; Li, X.; Kaneko, K.; Kan, K.; Ozaki, N.; Hijikata, Y.; Irle, S.; Itami, K., Cycloparaphenylene as a molecular porous carbon solid with uniform pores exhibiting adsorptioninduced softness. Chem. Sci. 2016, 7 (7), 4204-4210.

(22) Schaub, T. A.; Prantl, E. A.; Kohn, J.; Bursch, M.; Marshall, C. R.; Leonhardt, E. J.; Lovell, T. C.; Zakharov, L. N.; Brozek, C. K.; Waldvogel, S. R.; Grimme, S.; Jasti, R., Exploration of the Solid-State Sorption Properties of Shape-Persistent Macrocyclic Nanocarbons as Bulk Materials and Small Aggregates. J. Am. Chem. Soc. 2020, 142 (19), 8763-8775.

(23) Sicard, L.; Jeannin, O.; Rault-Berthelot, J.; Quinton, C.; Poriel, C., [4]Cyclofluorene: Unexpected Influence of Alkyl Chain Length. ChemPlusChem 2018, 83 (9), 874-880.

(24) Della Sala, P.; Buccheri, N.; Sanzone, A.; Sassi, M.; Neri, P.; Talotta, C.; Rocco, A.; Pinchetti, V.; Beverina, L.; Brovelli, S.; Gaeta, C., First demonstration of the use of very large Stokes shift cycloparaphenylenes as promising organic luminophores for transparent luminescent solar concentrators. Chem. Comm. 2019, 55 (21), 3160-3163. (25) Heras Ojea, M. J.; Van Raden, J. M.; Louie, S.; Collins, R.; Pividori, D.; Cirera, J.; Meyer, K.; Jasti, R.; Layfield, R. A., SpinCrossover Properties of an Iron(II) Coordination Nanohoop. Angew. Chem. Int. Ed. 2021, 60 (7), 3515-3518.

(26) Lin, J. B.; Darzi, E. R.; Jasti, R.; Yavuz, I.; Houk, K. N., SolidState Order and Charge Mobility in [5]- to [12]Cycloparaphenylenes. $J$. Am. Chem. Soc. 2019, 141 (2), 952-960.

(27) Lovell, T. C.; Fosnacht, K. G.; Colwell, C. E.; Jasti, R., Effect of curvature and placement of donor and acceptor units in cycloparaphenylenes: a computational study. Chem. Sci. 2020, 11 (44), 12029-12035

(28) Graham, C.; Moral, M.; Muccioli, L.; Olivier, Y.; PérezJiménez, Á. J.; Sancho-García, J. C., N-doped cycloparaphenylenes: Tuning electronic properties for applications in thermally activated delayed fluorescence. Int. J. Quantum Chem. 2018, 118 (12).

(29) Canola, S.; Graham, C.; Pérez-Jiménez, Á. J.; Sancho-García, J.-C.; Negri, F., Charge transport parameters for carbon based nanohoops and donor-acceptor derivatives. Phys. Chem. Chem. Phys. 2019, 21 (4), 2057-2068.

(30) Bredas, J. L.; Marder, S. R., The WSPC References on Organic Electronics: Organic Semi-Conductors. World Scientific, 2016 (31) Jiang, Z.-Q.; Poriel, C.; Leclerc, N., Emerging organic electronics. Mater. Chem. Front. 2020, 4 (9), 2497-2498.

(32) Liu, Y.-Y.; Lin, J.-Y.; Bo, Y.-F.; Xie, L.-H.; Yi, M.-D.; Zhang, X.-W.; Zhang, H.-M.; Loh, T.-P.; Huang, W., Synthesis and Crystal Structure of Highly Strained [4]Cyclofluorene: Green-Emitting Fluorophore. Org. Lett. 2016, 18 (2), 172-175.

(33) Kayahara, E.; Sun, L.; Onishi, H.; Suzuki, K.; Fukushima, T.; Sawada, A.; Kaji, H.; Yamago, S., Gram-Scale Syntheses and Conductivities of [10]Cycloparaphenylene and Its Tetraalkoxy Derivatives. J. Am. Chem. Soc. 2017, 139 (51), 18480-18483.

(34) Coropceanu, V.; Cornil, J.; da Silva Filho, D. A.; Olivier, Y.; Silbey, R.; Brédas, J.-L., Charge Transport in Organic Semiconductors. Chem. Rev. 2007, 107 (4), 926-952.

(35) Kayahara, E.; Sun, L.; Onishi, H.; Suzuki, K.; Fukushima, T.; Sawada, A.; Kaji, H.; Yamago, S., Gram-Scale Syntheses and Conductivities of [10]Cycloparaphenylene and Its Tetraalkoxy Derivatives. J. Am. Chem. Soc. 2017, 139 (51), 18480-18483.
(36) Lucas, F.; Sicard, L.; Jeannin, O.; Rault-Berthelot, J.; Jacques, E.; Quinton, C.; Poriel, C., [4]Cyclo-N-ethyl-2,7-carbazole: Synthesis, Structural, Electronic and Charge Transport Properties. Chem. Eur. J. 2019, 25, 7740-7748.

(37) Kamatham, N.; Ibraikulov, O. A.; Durand, P.; Wang, J.; Boyron, O.; Heinrich, B.; Heiser, T.; Lévêque, P.; Leclerc, N.; Méry, S. On the Impact of Linear Siloxanated Side Chains on the Molecular SelfAssembling and Charge Transport Properties of Conjugated Polymers. Adv. Funct. Mater. 2021, 31 (6), 2007734.

(38) Graham, K. R.; Cabanetos, C.; Jahnke, J. P.; Idso, M. N.; El Labban, A.; Ngongang Ndjawa, G. O.; Heumueller, T.; Vandewal, K.; Salleo, A.; Chmelka, B. F.; Amassian, A.; Beaujuge, P. M.; McGehee, M. D., Importance of the Donor:Fullerene Intermolecular Arrangement for High-Efficiency Organic Photovoltaics. J. Am. Chem. Soc. 2014, 136 (27), 9608-9618.

(39) Kuroda, Y.; Sakamoto, Y.; Suzuki, T.; Kayahara, E.; Yamago, S., Tetracyclo(2,7-carbazole)s: Diatropicity and Paratropicity of Inner Regions of Nanohoops. J. Org. Chem. 2016, 81 (8), 3356-3363.

(40) Yamago, S.; Watanabe, Y.; Iwamoto, T., Synthesis of [8]Cycloparaphenylene from a Square-Shaped Tetranuclear Platinum Complex. Angew. Chem. Int. Ed. 2010, 49 (4), 757-759.

(41) Sun, Z.; Sarkar, P.; Suenaga, T.; Sato, S.; Isobe, H., BeltShaped Cyclonaphthylenes. Angew. Chem. Int. Ed. 2015, 54 (43), 1280012804

(42) Xia, J.; Bacon, J. W.; Jasti, R., Gram-scale synthesis and crystal structures of [8]- and [10]CPP, and the solid-state structure of C60@[10]CPP. Chem. Sci. 2012, 3 (10), 3018-3021.

(43) Segawa, Y.; Omachi, H.; Itami, K., Theoretical Studies on the Structures and Strain Energies of Cycloparaphenylenes. Org. Lett. 2010, 12 (10), 2262-2265.

(44) Bond, A. D.; Davies, J. E., n-Decane. Act. Cryst. E 2002, 58 (2), o196-0197.

(45) Mallick, S.; Maddala, S.; Kollimalayan, K.; Venkatakrishnan, P., Oxidative Coupling of Carbazoles: A Substituent-Governed Regioselectivity Profile. J. Org. Chem. 2019, 84 (1), 73-93.

(46) Hapiot, P.; Lagrost, C.; Le Floch, F.; Raoult, E.; RaultBerthelot, J., Comparative Study of the Oxidation of Fluorene and 9,9Disubstituted Fluorenes and Their Related 2,7'-Dimers and Trimer. Chem. Mater. 2005, 17 (8), 2003-2012.

(47) Fenn, R. J.; Krantz, K. W.; Stuart, J. D., Anodic Oxidation of Two Polychlorinated Biphenyls. J. Electrochem. Soc. 1976, 123 (11) 1643-1647.

(48) Sicard, L.; Quinton, C.; Lucas, F.; Jeannin, O.; RaultBerthelot, J.; Poriel, C., 1-Carbazolyl Spirobifluorene: Synthesis, Structural, Electrochemical, and Photophysical Properties. J. Phys. Chem. C 2019, 123 (31), 19094-19104.

(49) Ambrose, J. F.; Nelson, R. F., Anodic Oxidation Pathways of Carbazoles. J. Electrochem. Soc. 1968, 115 (11), 1159.

(50) Poriel, C.; Ferrand, Y.; Le Maux, P.; Rault-Berthelot, J.; Simonneaux, G., Organic Cross-Linked Electropolymers as Supported Oxidation Catalysts: Poly((tetrakis(9,9،spirobifluorenyl)porphyrin)manganese) Films. Inorg. Chem. 2004, 43 (16), 5086-5095.

(51) Poriel, C.; Ferrand, Y.; Le Maux, P.; Paul-Roth, C.; Simonneaux, G.; Rault-Berthelot, J., Anodic oxidation and physicochemical properties of various porphyrin-fluorenes or spirobifluorenes: Synthesis of new polymers for heterogeneous catalytic reactions. J. Electroanal. Chem. 2005, 583 (1), 92-103.

(52) Rault-Berthelot, J.; Poriel, C.; Justaud, F.; Barrière, F., Anodic oxidation of indenofluorene. Electrodeposition of electroactive poly(indenofluorene). New J. Chem. 2008, 32 (7), 1259-1266.

(53) Zhu, H.; Badía-Domínguez, I.; Shi, B.; Li, Q.; Wei, P.; Xing, H.; Ruiz Delgado, M. C.; Huang, F., Cyclization-Promoted Ultralong Low-Temperature Phosphorescence via Boosting Intersystem Crossing. J. Am. Chem. Soc. 2021, 143 (4), 2164-2169.

(54) Poriel, C.; Rault-Berthelot, J.; Thiery, S.; Quinton, C.; Jeannin, O.; Biapo, U.; Tondelier, D.; Geffroy, B., $9 H$-Quinolino[3,2,1$k$ ]phenothiazine: A New Electron-Rich Fragment for Organic Electronics. Chem. Eur. J. 2016, 22 (50), 17930-17935.

(55) Thiery, S.; Tondelier, D.; Geffroy, B.; Jeannin, O.; RaultBerthelot, J.; Poriel, C., Modulation of the Physicochemical Properties of Donor-Spiro-Acceptor Derivatives through Donor Unit Planarisation: Phenylacridine versus Indoloacridine-New Hosts for Green and Blue 
Phosphorescent Organic Light-Emitting Diodes (PhOLEDs). Chem. Eur. J. 2016, 22 (29), 10136-10149.

(56) Thirion, D.; Romain, M.; Rault-Berthelot, J.; Poriel, C., A- $\pi-$ $\mathrm{A}, \mathrm{D}-\pi-\mathrm{D}$ and $\mathrm{D}-\pi-\mathrm{A}$ blue emitting fluorophores based on dispiro[fluorene-9,6'-indeno[1,2-b]fluorene-12',9"'-fluorene]. Mater. Adv. 2021, 2, 1271-1283.

(57) Bondi, A., van der Waals Volumes and Radii. J. Phys. Chem. 1964, 68 (3), 441-451.

(58) Sancho-García, J. C.; Moral, M.; Pérez-Jiménez, A. J., Effect of Cyclic Topology on Charge-Transfer Properties of Organic Molecular Semiconductors: The Case of Cycloparaphenylene Molecules. J. Phys. Chem. C 2016, 120 (17), 9104-9111.

(59) Peltier, J.-D.; Heinrich, B.; Donnio, B.; Jeannin, O.; RaultBerthelot, J.; Jacques, E.; Poriel, C., N-Cyanoimine as an electronwithdrawing functional group for organic semiconductors: example of dihydroindacenodithiophene positional isomers. J. Mater. Chem. C 2018, 6 (48), 13197-13210.

(60) Peltier, J.-D.; Heinrich, B.; Donnio, B.; Rault-Berthelot, J.; Jacques, E.; Poriel, C., Electron-Deficient Dihydroindaceno-Dithiophene Regioisomers for n-Type Organic Field-Effect Transistors. ACS Appl. Mater. Interfaces. 2017, 9 (9), 8219-8232.

(61) Bebiche, S.; Cisneros-Perez, P.; Mohammed-Brahim, T.; Harnois, M.; Rault - Berthelot, J.; Poriel, C.; Jacques, E., Influence of the gate bias stress on the stability of n-type Organic Field-Effect Transistors based on Dicyanovinylenes-Dihydroindenofluorene semiconductors. Mater. Chem. Front. 2018, 2, 1631-1641.

(62) Marcus, R. A., Electron transfer reactions in chemistry. Theory and experiment. Rev. Mod. Phys. 1993, 65 (3), 599-610.

(63) Troisi, A.; Orlandi, G., Dynamics of the Intermolecular Transfer Integral in Crystalline Organic Semiconductors. J. Phys. Chem. A 2006, 110 (11), 4065-4070.

(64) Troisi, A., Prediction of the Absolute Charge Mobility of Molecular Semiconductors: the Case of Rubrene. Adv. Mater. 2007, 19 (15), 2000-2004

(65) Tsutsui, Y.; Schweicher, G.; Chattopadhyay, B.; Sakurai, T.; Arlin, J.-B.; Ruzié, C.; Aliev, A.; Ciesielski, A.; Colella, S.; Kennedy, A. R.; Lemaur, V.; Olivier, Y.; Hadji, R.; Sanguinet, L.; Castet, F.; Osella, S.; Dudenko, D.; Beljonne, D.; Cornil, J.; Samorì, P.; Seki, S.; Geerts, Y. H., Unraveling Unprecedented Charge Carrier Mobility through Structure Property Relationship of Four Isomers of Didodecyl[1]benzothieno[3,2b][1]benzothiophene. Adv. Mater. 2016, 28 (33), 7106-7114.

(66) Cornil, J.; Calbert, J. P.; Brédas, J. L., Electronic Structure of the Pentacene Single Crystal: Relation to Transport Properties. J. Am. Chem. Soc. 2001, 123 (6), 1250-1251.

(67) Scott, J. C., Metal-organic interface and charge injection in organic electronic devices. J. Vac. Sci. Technol. A 2003, 21 (3), 521-531. (68) Hill, I. G.; Rajagopal, A.; Kahn, A.; Hu, Y., Molecular level alignment at organic semiconductor-metal interfaces. Appl. Phys. Lett. 1998, 73 (5), 662-664.

(69) Troisi, A.; Orlandi, G.; Anthony, J. E., Electronic Interactions and Thermal Disorder in Molecular Crystals Containing Cofacial Pentacene Units. Chem. Mater. 2005, 17 (20), 5024-5031.

(70) Martinelli, N. G.; Olivier, Y.; Athanasopoulos, S.; Ruiz Delgado, M.-C.; Pigg, K. R.; da Silva Filho, D. A.; Sánchez-Carrera, R. S.; Venuti, E.; Della Valle, R. G.; Brédas, J.-L.; Beljonne, D.; Cornil, J., Influence of Intermolecular Vibrations on the Electronic Coupling in Organic Semiconductors: The Case of Anthracene and Perfluoropentacene. ChemPhysChem 2009, 10 (13), 2265-2273.

(71) Schweicher, G.; D'Avino, G.; Ruggiero, M. T.; Harkin, D. J.; Broch, K.; Venkateshvaran, D.; Liu, G.; Richard, A.; Ruzié, C.; Armstrong, J.; Kennedy, A. R.; Shankland, K.; Takimiya, K.; Geerts, Y. H.; Zeitler, J. A.; Fratini, S.; Sirringhaus, H., Chasing the "Killer" Phonon Mode for the Rational Design of Low-Disorder, High-Mobility Molecular Semiconductors. Adv. Mater. 2019, 31 (43), 1902407. 


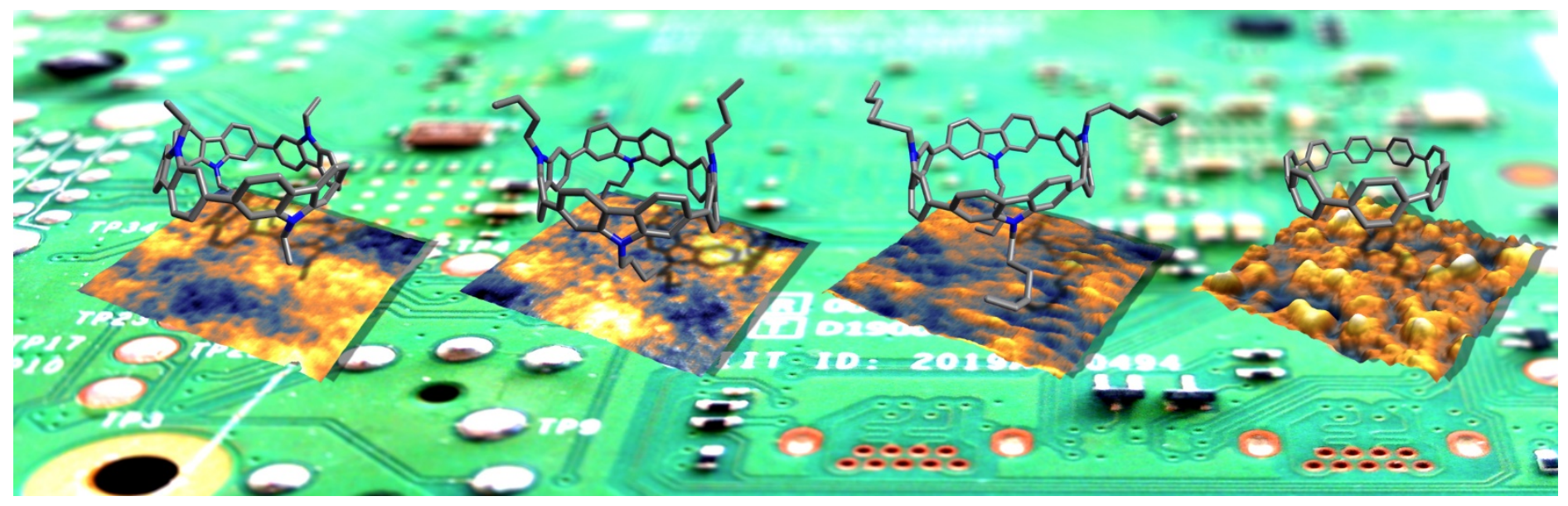

